\title{
DIFUSIÓN LÉXICA, CAMBIO SEMÁNTICO Y GRAMATICALIZACIÓN: EL CASO DE HABER + PARTICIPIO EN ESPAÑOL ANTIGUO*
}

\author{
JAVIER RODRfGUEZ MOLINA
}

Instituto de la Lengua Española. CSIC

\section{INTRODUCCION}

La existencia de la perífrasis haber + pp (participio), embrión de los tiempos anteriores (TA) del español actual (he cantado), está bien atestiguada en castellano antiguo, asi como en otras variedades romances medievales. El valor de anterioridad que caracteriza a estas construcciones lo podemos encontrar ya inequívocamente documentado en la lengua medieval (1). Sin embargo, en español antiguo el verbo haber tenía otros muchos usos, algunos hoy desaparecidos: servía para expresar la posesión en sus varias acepciones (2), para la formación de construcciones resultativas transitivas activas (3) y también conocía usos impersonales (4).

1) Por amor de Rey Alffonfro, que de tierra me a echado (PMC 1240)

2) Que he auer $\tau$ tierra $\tau$ oro $\tau$ onor (PMC 2495)

3) Las armas auien prefas $\tau$ fedien fobre los cauallos (PMC 1001)

4) Todos eran Ricos quantos que alli ha (PMC 1215)

Para los usos ejemplificados en (2-3), el español antiguo disponía también de otro verbo de posesión, tener, que finalmente acabó consolidándose como verbo exclusivo de posesión y como verbo auxiliar de las perifrasis resultativas transitivas. Las construcciones de (3) preceden históricamente y son el origen de las estructuras de (1) pues, como han señalado diversos estudios, la gramaticalización de tiempos verbales que expresan anterioridad a partir de construc-

- Este trabajo ha sido realizado gracias a una beca FPU (AP2002-0363) de la Secretaría de Estado de Universidades. Quiero agradecer a Concepción Company, Javier Elvira, Leonardo Gó mez Torrego y, especialmente a Inés Femández-Ordónez, la cuidadosa lectura previa y las sugerencias que han mejorado esta versión final.

RFE, LXXXIV, 2004, 1. , págs. 169-209 
ciones resultativas es un fenómeno bien atestiguado y estudiado tipológicamente ${ }^{1}$.

Un proceso de gramaticalización puede ser definido como «the change whereby lexical items and constructions come in certain linguistic contexts to serve grammatical functions and, once grammaticalized, continue to develop new grammatical functions ${ }^{2}$. Es un proceso irreversible y gradual, por lo regular unidireccional, de debilitamiento del significado referencial de las formas, que progresivamente adquieren un significado gramatical más abstracto. En latín, el verbo habere, unido a cierto tipo de participios, indicaba el resultado de la acción significada por el verbo: habere y el participio funcionaban como dos unidades léxicas independientes que conservaban plenamente su significado referencial (5). Por el contrario, en español actual el verbo haber se ha gramaticalizado como auxiliar temporal: la construcción entera hace referencia a la anterioridad verbal, no denota ya necesariamente un valor resultativo y ha rigidizado su estructura sintáctica, de modo que haber y el participio no son ya unidades independientes (6). Sin duda, los hechos sintácticos (pérdida de la concordancia del participio, fijación del orden sintáctico auxiliar-participio, pérdida de la doble auxiliaridad ser/haber y generalización exclusiva de haber, imposibilidad de interpolar elementos entre auxiliar y participio) son los que han recibido una atención privilegiada por parte de los investigadores ${ }^{3}$, quedando los problemas semánticos en un segundo plano.

\footnotetext{
1 Joan L. Bybee, Revere Perkins y William Pagliuca, The evolution of grammar; Tense, aspect and modality in the languages of the world, Chicago, University of Chicago Press, 1994, pág. 68. Para las vicisitudes de haber y tener como verbos de posesión, vid. Eva Seifert, «"Haber" y "Tener" como expresiones de la posesión en español», Revista de Filología Española, XVII, 1930, págs. 233-276 y 345-389 y Axel Hernández-Díaz, «Verbos de posesión: la competencia de haber y tenen, en C. Company (dir.), Sintaxis histónica del español, tomo I: La frase yerbal, México, FCE y UNAM, en prensa.

${ }^{2}$ Paul J. Hopper y Elizabeth C. Traugott, Grammaticalization, Cambridge, Cambridge Unjversity Press, 2003, 2. ed, pág. 18.

${ }^{3}$ Puesto que esta parte del proceso es bien conocida, no voy a exterderme más en ella: remito al reciente estado de la cuestión de José M." García Martín, La formación de los tiempos compuestos en español medieval y clásico, Valencia, Univ. de Valencia, 2001. Sobre los ońgenes latinos de haber + pp son fundamentales los trabajos de Philip Thielmann, «Habere mit dem Partizip Perfektum Passivum», Archiv für Lateinische Lexikographie und Grammatik, 2, 1885, págs. 372-423 y 509-549; Nigel Vincent, «The development of the auxiliares HABERE and ESSE in Romance», en Studies on the Romance Verb, M. Harris y N. Vincent (eds.), London, Croom Helm, 1982, pags. 71-96; Harm Pinkster, «The Strategy and Chronology of the Development of Future and Perfect Tense Auxiliaries in Latin» en M. Harris y P. Ramat (eds.), Historical Development of Auxiliaries, Berlin, Mouton de Gruyter, 1987, pags. 193-223; Gianpaolo Salvi, «Syntactic Restructuring in the Evolution of Romance Auxiliaries», en M. Harris y P. Ramat (eds.), Historical Development of Auxiliaries op. cit., pags. 225-236 y García Martín, op. cit., págs. 28-50. En cuanto al español medieval, las principales referencias son: Emilio Alarcos Llorach, «Perfecto simple y perfecto compuesto en español», Revista de Filología Española, XXXI, 1947, págs. 108-139; Concepción Company, «Sintaxis y valores de los tiempos
} 
5) Caesar urbem occupatam habet 'César tiene la ciudad ocupada' / 'César tiene ocupada la ciudad' (necesariamente, César ha ocupado la ciudad y la mantiene ocupada)

6) César ha ocupado la ciudad 'César ha ocupado la ciudad' / * César la ciudad ocupada ha $/ *$ César ha la ciudad ocupada' (César ha ocupado la ciudad pero no necesariamente la mantiene aún en su poder)

La gramaticalización de haber + pp se ha atribuido a un mecanismo de reanálisis ${ }^{4}$ sintáctico (7) acompañado de una inferencia pragmática (por la que se enfoca la acción previa en detrimento del estado resultante) que posibilita el cambio semántico resultativo > tiempo anterior (8). Entre los factores que facilitaron este reanálisis, se han señalado principalmente tres: a) la identidad de sujetos, esto es, que el sujeto de habere y el sujeto del participio fueran el mismo favoreció que se entendiese un único sujeto para toda la secuencia, estrechando la relación de habere y el participio; b) el tipo de participio: parece que el paso de la noción de posesión a la de tieñpo anterior se vio favorecido con verbos de percepción física o conocimiento intelectual (en construcciones del tipo cognitum habeo, perspectum habeo) ${ }^{5}$, por la ya mencionada correferencia de los sujetos; c) la cercanía de habere y el participio, que contribuyó a un mayor grado de cohesión de la secuencia.

7) habere + (objeto + participio) $\rightarrow$ (habere + participio) + objeto

8) habeo litteras scriptas 'tengo cartas escritas' $\rightarrow$ he escrito cartas 'he escrito cartas'

El objetivo de esta investigación es analizar bajo qué condiciones operan los mecanismos de reanálisis y cambio semántico resultativo > tiempo anterior

compuestos en el español medieval», Nueva Revista de Filologia Hispánica, XXXIr: 2, 1983, págs. 235-256; Christopher Pountain, «Copulas, verbs of possession and auxiliaries in Old Spanish: The Evidence for Structurally Interdependent Changes», Bulletin of Hispanic Studies, LXII: 1985, págs. 337-355; Irene Andres-Suárez, El verbo español. Sistemas medievales y sistema clásico, Madrid, Gredos, 1994; Rafael Lapesa, Estudios de morfosintaxis histórica del español, Madrid, Gredos, 2000 (págs. 779-784) y Patrizia Romani, «Tiempos de formación romance I. Los tiempos compuestos», en C. Company (dir.), Sintaxis histórica del español, op. cit.

${ }^{4}$ Sobre el concepto de reanálisis y su aplicación a la sintaxis histórica, vid. Alice C. Harris y Lyle Campbell, Historical syntax in cross-linguistic perspective, Cambridge, Cambridge University Press, 1995, págs. 61-96 y 183-185. Especfficamente sobre el reanálisis de habere + pp, Pinkster, art. cit. y Salvi, art. cit.

${ }^{5}$ Hipótesis que se encuentra ya en Thielmann, art, cit. págs. 509-511 y que suscriben prácticamente todos los autores que han escrito sobre esta cuestiơn: Alarcos, art. cit. pág. 129; Vincent, art. cit. pág. 77; Pinkster, art. cit., págs. 200 y 204-205; Salvi, art, cit.; Hopper y Traugott, op. cit., págs. 62-63; García Martín, op. cit., pág. 33 y Romani, art. cit. No obstante, vid. las acertadas observaciones de Daniel Jacob, «A propos de la périphrase habeo + participe parfait passif», en Latin vulgaire et latin tardif $I V$, L. Callebat (ed), Hildesheim, Olms, 1995, págs. 367381 sobre los problemas que esta hipótesis y algunos otros aspectos de la reconstrucción tradicional plantean. 
en español antiguo, fundamentalmente a partir de un extenso corpus de documentos notariales (Corpus A, documentos de los siglos IX-XIII) y con el apoyo de algunos textos literarios primitivos (Corpus B, Poema de Mio Cid, Razón de Amor, Liber Regum, Cantar de Roncesvalles) ${ }^{6}$. Los datos obtenidos sugieren que el desarrollo del valor semántico de anterioridad de haber + pp fue un fenómeno gradual, orientado léxicamente y en el que intervinieron decisivamente el grado de transitividad del predicado, las condiciones aspectuales de la cláusula y ciertos factores de naturaleza pragmática concernientes a la relevancia discursiva.

La estructura de este trabajo es la siguiente: dedico la sección 2 a la delimitación teórica y conceptual de la anterioridad verbal, las construcciones resultativas y a la discusión de algunas cuestiones relativas al cambio linguístico. En 3 presento el corpus utilizado. La sección 4 trata sobre la adquisición de la anterioridad verbal, mientras que en 5 analizo los factores pragmático-discursivos que facilitaron el cambio semántico de haber + pp. Por último, el apartado 6 recoge las principales conclusiones de este estudio.

\section{CONSIDERACIONES TEÓRICAS}

\subsection{Delimitación de los conceptos 'Resultativo' y 'Tiempo Anterior'}

Como he indicado previamente, el giro haber + pp podía expresar tanto un valor de anterioridad (1) como un valor resultativo (3). Por lo tanto, parece necesario precisar, aunque sea brevemente, algunos conceptos teóricos relativos a los tiempos anteriores, las construcciones resultativas y las diferencias existentes entre ambas estructuras, puesto que nos serán útiles para la discusión posterior. La definición que me parece más ajustada para el concepto de tiempo compuesto y que he adoptado yo mismo es la que proporcionan Bybee, Perkins y Pagliuca ${ }^{7}$ para el término Anterior: «an anterior signals that the situation occurs prior to reference time and is relevant to the situation at reference time». Podemos caracterizar como tiempos anteriores aquellas formas verbales

${ }^{6}$ Las ediciones utilizadas son PMC = Cantar de Mio Cid. Texto, gramática y vocabulario, edición de Ramón Menéndez Pidal, Madrid, Espasa-Calpe, 1969, 4a ed.; RA = Enzo Franchini, El manuscrito, la lengua y el ser literario de la Razón de Amor, Madrid, CSIC, 1993; RONC = Ramón Menéndez Pidal, «Roncesvalles. Un nuevo cantar de gesta español del siglo XIII», Revista de Filologia Española, IV, 1917, págs. 105-204; LR = Louis Cooper, El Liber regum Estudio linguístico, Zaragoza, Institución «Fernando el Católico», 1960. Aunque no lo he incluido en el corpus B, citaré algunos ejemplos a lo largo del trabajo provenientes de Mil = Gonzalo de Berceo, Milagros de Nuestra Señora, edición de Fernando Baños. Estudio preliminar de Isabel Uría, Ваrcelona, Crítica, 1997. En todos los casos, y cuando es posible, cito por el testimonio paleográfico. Las referencias bibliográficas del Corpus A se encuentran bajo el \& 3 'El Corpus'.

7 Op. cit., pág. 54. 
que presentan las siguientes propiedades ${ }^{8}$ : I. Anterioridad: todo tiempo compuesto expresa un evento previo al punto de referencia temporal. II. Perfectividad: todo tiempo compuesto implica un límite temporal, ya que indica un evento perfectivo o delimitado, esto es, acabado. III. Relevancia presente: el evento previo denotado por el tiempo compuesto es relevante para los participantes del discurso.

El concepto 'límite' hace referencia a dos realidades distintas: cuando un evento télico alcanza su punto final, hablamos de límite material (como en Juan construyó una casa); cuando un evento, no necesariamente télico, se encuentra delimitado temporalmente hablamos de límite temporal (como en Juan durmió tres horas). Un límite material siempre implica un límite temporal, pero no a la inversa'. También es importante distinguir los conceptos 'relevancia presente' (current relevance) y 'resultado presente' (current result), ya que a menudo se ha identificado 'relevancia presente' con la continuación en el presente del resultado de un hecho pasado, definición que corresponde a 'resultado presente'. Adoptaré aquí la definición que proporcionan del concepto 'relevancia presente' Dahl y Hedin ${ }^{10}$ : «it means that the [previous] event has repercussions of some kind for the participants of the discourse situation». Pero, a menudo, esta repercusión de la acción previa no es inherente al significado del verbo, sino que depende del contexto donde se halla inserta la forma verbal. La diferencia entre 'relevancia presente' y 'resultado presente' es parecida a la que existe entre límite temporal y límite material: puede ser que ambas coincidan (como en mi padre ha muerto esta mañana, que expresa el resultado, ya que continúa estando muerto, pero también indica una relación de especial interés en el momento presente para los interlocutores) o puede que únicamente se exprese la relevancia presente (como en he hecho la cena, ya que puede seguir hecha o puedo habérmela comido).

Una construcción resultativa, como su propio nombre indica, expresa un estado resultante surgido de un evento previo. Los lingüistas han propuesto una serie de pruebas que permiten distinguir una construcción resultativa de un tiempo anterior ${ }^{11}$ :

Talmy Givón, Syntax: An Introduction, Ansterdam/Philadelphia, John Benjamins, 2001, vol. I, págs. 293-98; Nelson Cartagena, «Los tiempos compuestos» en I. Bosque y V. Demonte (dirs.), Gramática descriptiva de la lengua española, Madrid, Espasa Calpe, 1999, págs. 2935-2976.

9 Jouko Lindstedt, «The perfect-aspectual, temporal and evidential», en $O$. Dahl (ed.), Tense and Aspect in the languages of the world, Berlin/New York, Mouton de Gruyter, 2000, págs. 365-383 (pág. 368) y «Understanding perfectivity-understanding bounds», en P. Bertinetto, V. Bianchi, J. Higginbotham y $\mathbf{M}$. Squartini (eds.), Temporal reference, aspect and actionality, Torino, Rosenberg \& Sellier, 1995, vol. II, págs. 95-103.

10 Östen Dahl y Eva Hedin, «Current relevance and event reference», en Ö. Dahl (ed.), Tense and Aspect, op. cit., págs. 384-401 (pág. 391-92).

"1 La investigación tipologica sobre las construcciones resultativas comenzo a partir de la publicación del trabajo pionero de Vladimir P. Nedjalkov y Sergei J. Jaxontov, «The typology of 
I. Un TA puede formarse a partir de cualquier verbo, mientras que el resultativo presenta unas restricciones léxicas muy fuertes: solo los verbos télicos dan lugar a construcciones resultativas.

II. El TA no afecta a la valencia del verbo, mientras que en el resultativo se produce un cambio de diátesis: el sujeto de una construcción resultativa a menudo corresponde al objeto de su correlato no resultativo. La construcción resultativa es normalmente intransitiva.

III. El resultativo implica que el estado alcanzado se mantenga, de modo que hay coincidencia entre el límite temporal y el límite material en el punto de referencia. En cambio, el TA no presupone necesariamente esta coincidencia: tengo hecha la cena presupone que la he hecho (límite temporal) y que ésta permanece hecha (límite material), pero he hecho la cena no implica necesariamente que la cena esté aún hecha. De esta característica podemos deducir el carácter fundamentalmente aspectual del resultativo, mientras que el TA es una forma de naturaleza eminentemente temporal.

IV. Resultativos y TA muestran diferencias a la hora de combinarse con expresiones adverbiales. Solo los resultativos pueden combinarse con adverbios de duración ilimitada como 'aún' o 'todavía" ("aún he hecho la cena / aún tengo hecha la cena; todavía tengo el ordenador estropeado / *todavla he estropeado el ordenador)

V. Al menos en espafol, las construcciones resultativas transitivas no admiten predicados secundarios, mientras que los TA sí; Juan ha limpiado el coche cansado / *Juan tiene el coche limpiado cansado. En español antiguo, cuando haber + pp se presenta acompañado de un predicado secundario no admite otra lectura que la temporal: todos son exidos, las puertas dexadas an abiertas (PMC 461) 'han dejado las puertas abiertas' $/{ }^{*}$ 'tienen dejadas las puertas abiertas'

Los verbos que dan lugar a construcciones resultativas denotan aspectualmente acciones o procesos télicos, esto es, delimitados (I) que desembocan en un estado resultante del objeto (II). En español antiguo la estructura resultativa más frecuente era una construcción perifrástica con el verbo ser (9) o con el verbo estar (10). Junto a estas estructuras resultativas intransitivas, la lengua antigua disponía de dos construcciones resultativas transitivas en las que intervenían los verbos haber 'tener' (3) y tener 'tener' (11).

9) Todos fe cuedan que ferido ef de muert (PMC 3688)

10) Metióli so los piedes do estava colgado (Mil 150a)

11) El rey don Pedro towo Uesca cercada (LR 17, 27)

En resumidas cuentas, en las lenguas que poseen resultativos y tiempos anteriores es posible aplicar ciertas pruebas lingiísticas que permiten diferenciar

resultative constructions» en V. P. Nedjalkov (ed.), Typology of resultative constructions, Amsterdam/Philadelphia, John Benjamins, 1988, págs. 3-62 (pág. 15-16) y los articulos reunidos en ese volumen. Joan $\mathbf{L}$. Bybee y Östen Dahl, «The creation of tense and aspect systems in the languages of the world», Studies in Language, 13/1, 1989, págs. 51-103 (págs. 68-69) y, en especial, el libro de Bybee, Perkins y Pagliuca, op. cit., cap. 3 constituyen dos referencias imprescindibles para la delimitación teórica de las categorías resultativo/tiempo anterior. 
estas dos formas gramaticales. El español antiguo, al igual que otras lenguas, se sirve de la misma construcción (haber + pp) para formar TA (1) y resultativos (13), lo cual dificulta la aplicación de las pruebas I-V. Por ello, a continuación estableceré con mayor precisión en qué tipo de estructuras resultativas pudo originarse el reanálisis y bajo qué mecanismos pudo producirse el cambio semántico resultativo > tiempo anterior.

\subsection{Reanálisis, relevancia pragmática y tipos de construcciones resultativas}

Es evidente que no todas las construcciones resultativas transitivas pueden ser reanalizadas (7): existen casos que no permiten el reanálisis (12). Como ya hemos apuntado, que la estructura haber + pp permita ser reanalizada es un requisito indispensable para que a su vez se produzca el cambio semántico. Por lo tanto, la primera cuestión que debe plantearse gira en torno al problema de la delimitación precisa de los contextos más afines al reanálisis (7) y al cambio semántico (8). Básicamente, es posible distinguir tres tipos de estructuras diferentes para la construcción haber $+\mathrm{pp}$, estructuras a las que convencionalmente catalogaremos como Tipos Nominales, Resultativas tipo I y Resultativas tipo II.

En los Tipos Nominales (12 a-c), el participio funciona de forma idéntica a un adjetivo y habere conserva su significado inherente de posesión, ya sea la posesión de carácter alienable (12a) o inalienable (12b). Bajo los ejemplos de (12b) podemos introducir también aquellos ejemplos en los que el participio expresa una cualidad de carácter transitorio relativa a un objeto de carácter inalienable (12c). En todos los ejemplos de (12), caracterizados como 'Tipos Nominales', el significado de la combinación de habere + $\mathrm{OD}+$ pp es puramente composicional $^{12}$. Es evidente que ninguna de las estructuras de (12) constituye el antecedente de los TA, ya que no dan lugar a posibilidad de reanálisis alguno.

12) a. Cibum tibi et familiae curet uti coctum habeat (Catón $R R$ 143, 2) 'que [ella] tenga comida cocinada para ti y para los sirvientes'

b. Serra nuncupata, quia serratam cristam habet (S. Isid. Etym. 12, 6, 16) 'Se llama pez sierra porque tiene la cresta serrada'

c. si iumentum cambam percussam habuerit (Mul. Chironis 47) 'si el caballo tuviere una piema rota"

Por el contrario, en (13 a-c) el participio ejerce una función predicativa. Estos ejemplos se integran en un segundo tipo de estructuras de habere + pp

${ }^{12}$ Los ejemplos (13 b-c, 14b) están tomados de Andrés-Suărez, op. cit. $(12 a, 14 a, 14 c)$ de Pinkster art. cit. (12c) y (14d) de Jacob, "A propos de la périphrase habeo + participe», art. cit. Los ejemplos (12b) y (13a) los he recogido yo mismo de San Isidoro de Sevilla, Etimologias: edición bülingüe, texto latino, versión española y notas por José Oroz Reta y Manuel A. Marcos Casquero, Madrid, Editorial Católica, 1982-83, 2 vols. 
que son ya construcciones resultativas, pues expresan el estado resultante de uno de los participantes, codificado como el OD de la construcción; estado resultante que generalmente es relevante para otro participante, codificado como sujeto. Denominaré a este tipo de construcciones Resultativas tipo I. Además de este significado proposicional, estas construcciones pueden dar lugar a dos inferencias: a) el resultado presente es consecuencia de un evento anterior; b) este evento anterior ha sido realizado por un agente, inespecificado como tal en la construcción resultativa.

Las construcciones Resultativas tipo I tienen dos posibles lecturas según interpretemos que hay o no correferencia de sujetos. Por un lado, existen ejemplos que de ninguna forma permiten interpretar que los sujetos son correferentes y, por tanto, tampoco admiten cambio semántico alguno, ya que conservan siempre su significado resultativo (13a). Por otro lado, cuando la correferencia de sujetos es posible, esta lo es de manera opcional y no obligatoria. En efecto, en (13b) tanto cabe interpretar que el sujeto de habent es el mismo que tiene las riquezas y las ha colocado (correferencia $\sqrt{ }$ ) o que el sujeto que puso las riquezas $\mathrm{y}$ el que las tiene son actantes diferentes (correferencia $\mathrm{X}$ ), solo la primera interpretación podría dar lugar al cambio semántico. Sucede lo mismo en $(13 c)$.

13) a. lanterna inde vocatur quod lucem interius habeat clausam (S. Isid. Etym. 20, $10,7)$ 'se llama linterna porque tiene encerrada una luz en su interior'

b. [equites romani] in ea provincia pecunias magnas collocatas habent (Cic. Leg. Manil 18) 'tienen grandes sumas de dinero invertidas en esa provincia'

c. Ubi clausum lacu ac montibus et circumfusum suis copiis habuit hostem (Livio, $A b$ Urbe Condita XXII, 4, 5) 'tenía a su enemigo encerrado entre el lago y las montañas y rodeado de sus propias tropas'

Puede darse el caso de que el sujeto de la construcción resultativa y el sujeto del evento previo sean necesariamente el mismo, tal y como sucede en (14 a-d), construcciones a las que denominare Resultativas tipo I. La correferencia explícita y obligatoria de sujetos que caracteriza a estas estructuras obedece a una estrategia pragmática precisa: destacar el interés, participación o especial relevancia que para el sujeto posee el estado resultante. En efecto, en este tipo de construcciones, más que el estado resultante del objeto, la relevancia pragmática se focaliza en las repercusiones que el estado resultante tiene para el sujeto, que generalmente se presenta como el autor del evento télico denotado por haber + pp y suele revestir un carácter personal.

14) a. Nam et capillos nostros ipse utique creavit et numeratos habet (S. Agust. Serm. 62,10,15) 'porque él ha creado nuestros cabellos y los tiene contados'

b. Clodii animum perspectum habeo, cognitum, iudicatum (Cic. Ad Bnt. 1, 1, 1) 
c. si miles qui habebat iam factum testamentum aliud fecisset (Ulp. Org. 29, 1, 19)

d. Rogo te, habe me excusatum (Vulg. Luc., 14, 18) 'te lo mego, tenme por excusado'

Únicamente si existe correferencia explícita entre el sujeto de habere y el sujeto del participio puede producirse el reanálisis, y únicamente si bay reanálisis puede tener lugar la reinterpretación semántica de la perífrasis: mediante una inferencia de tipo metonímico ${ }^{13}$, el hablante reinterpreta el contenido pragmático de anterioridad (contiguo al significado de estado resultante) como parte integrante del significado de haber + pp. Este hecho coloca a las Resultativas tipo II como el contexto idóneo de gramaticalización de los TA, ya que reúnen más requisitos que las otras dos estructuras. De hecho, en latín existen casos (14 a-c) en los que es imposible dilucidar con plena certeza si nos encontramos ante un TA o ante una estructura resultativa aunque, en mi opinión, considero preferible caracterizar como resultativos y no como TA los ejemplos (14 a-d), puesto que existen argumentos fundados para pensar que los TA son una adquisición de las lenguas romances y no una innovación del sistema verbal latino ${ }^{14}$.

En las tablas siguientes sintetizo gráficamente las principales ideas expuestas a lo largo de este apartado: la tabla 1 muestra las diferencias entre Tipos Nominales, Resultativas tipo I y Resultativas tipo II, mientras que la tabla 2 recoge y resume las propiedades de los dos tipos de construcciones resultativas y los TA.

${ }^{13}$ Ulrich Detges, «Time and Truth: The grammaticalization of resultatives and perfects within a theory of subjectification», Studies in Language, 24:2, 2000, págs. 345-377 (pág. 361). Tomo de Detges los términos 'resultativo tipo I' y 'resultativo tipo II', aunque mi aplicación de estos términos difiere de la propuesta por el autor alemán, fundamentalmente porque considero que la correferencia explícita de sujetos en las tipo II es exclusivamente sintáctica, ya que no necesariamente el sujeto de habere y el del participio tienen que tener el papel temático de agente, como quiere Detges: existen resultativas tipo II donde el sujeto no es un agente, sino un experimentante (esta película ya la tengo muy vista, fengo entendido que no iba a venir).

14 La cronología de habere + pp es un tema problemático y aún en discusión, vid. el estado de la cuestión que presenta Garcfa Martín, op. cit., págs. 35-40. Por mi parte, considero que el uso de habere + pp como TA no se produjo antes de los siglos VI-vII en Francia (aunque Gregorio de Tours es el primer escritor donde podemos observar ejemplos claros de TA, estos no superan la docena en dos obras de extensión tan considerable como las Vitae Patrum y la Historia Francorum) y, a juzgar por la documentación utilizada en este trabajo, en época más tardía en Hispania. La documentación visigoda que se nos ba conservado y las crónicas latinas peninsulares corroboran la hipotesis del origen romance (y no latino) de los TA, puesto que los ejemplos de habere + pp que he documentado en este tipo de textos son escasísimos. Linguísticamente, presentan todas las características propias de las construcciones resultativas. Un estudio detallado de este tipo de documentos podrá encontrarse en mi tesis doctoral sobre la génesis y desarrollo de los TA desde el latín tardío al español antiguo y otras lenguas románicas (Universidad Autónoma de Madrid, en preparación). 
TABLA 1

Diferencias entre Tipos Nominales, Resultativas tipo I y Resultativas tipo II

\begin{tabular}{|c|c|c|c|}
\hline & $\begin{array}{c}\text { Posibilidad de } \\
\text { Reanálisis }\end{array}$ & Correferencia Sujeros & Posibilidad de Cambio semántico \\
\hline Tipo Nominal & $\mathrm{X}$ & $\mathbf{X}$ & $\mathbf{X}$ \\
\hline $\begin{array}{c}\text { Resultativo } \\
\text { Tipo I }\end{array}$ & $\sqrt{ } / \mathrm{X}$ & $\sqrt{ } / \mathrm{X}$ & $\sqrt{ } / \mathrm{X}$ \\
\hline $\begin{array}{c}\text { Resultativo } \\
\text { Tipo II }\end{array}$ & $\sqrt{ }$ & $\sqrt{ }$ & $\sqrt{ }$ \\
\hline
\end{tabular}

TABLA 2

Resultativas tipo I, Resultativas tipo II y TA

\begin{tabular}{|c|c|c|c|c|}
\hline & $\begin{array}{c}\text { Relacion entre } \\
\text { los sujetos }\end{array}$ & Significado & Contexto & $\begin{array}{c}\text { Foco de } \\
\text { relevancia }\end{array}$ \\
\hline $\begin{array}{c}\text { Resultativo } \\
\text { Tipo I }\end{array}$ & $\begin{array}{c}\text { 2 Sujetos, no } \\
\text { necestriamente } \\
\text { comeferentes }\end{array}$ & $\begin{array}{c}\text { Resultado } \\
\text { presente }\end{array}$ & Evento anterior & Objeto \\
\hline $\begin{array}{c}\text { Resultativo } \\
\text { Tipo II }\end{array}$ & $\begin{array}{c}\text { 2 Sujetos, necesariamente } \\
\text { correferentes }\end{array}$ & $\begin{array}{c}\text { Resultado } \\
\text { presente }\end{array}$ & Evento anterior & Sujeto \\
\hline $\begin{array}{c}\text { Tiempo } \\
\text { Anterior }\end{array}$ & Un único sujeto & $\begin{array}{c}\text { Evento } \\
\text { anterior }\end{array}$ & $\begin{array}{c}\text { Relevancia presente } \\
\text { (con positle mantenimiento del } \\
\text { estado resultante) }\end{array}$ & $\begin{array}{c}\text { Punto de referencja } \\
\text { temporal }\end{array}$ \\
\hline
\end{tabular}

\subsection{Gramaticalización y cambio lingüístico}

Muchos de los estudios que desde la perspectiva de Ia gramaticalización han abordado la evolución de los TA manejan una concepción del cambio lingǘrstico centrada exclusivamente en la innovación ${ }^{15}$. No obstante, la innovación es solo la fase inicial del cambio linguíístico, y puede que no sea la más decisiva. Una innovación gramatical solo adquiere carta de naturaleza como cambio linguístico cuando, tras un proceso de selección, alcanza un grado de difusión y aceptación lo suficientemente amplio (en la estructura lingüística y en la estructura social de una comunidad de habla) como para que pueda considerarse parte integrante de la gramática. Por lo tanto, el cambio lingüístico abarca al menos tres etapas: Innovación, Selección y Difusión ${ }^{16}$.

Un proceso de gramaticalización, como es bien sabido, no afecta a todos los miembros de una categoría de forma homogénea, sino que constituye un continuum que avanza de forma progresiva ${ }^{17}$. La teoría del cambio linguístico

Is Vid. la crítica de William Croft, Explaining language change. An evolutionary approach, London, Longman, 2000, pág. 63.

${ }^{16}$ Eugenio Coseriu, Sincronta, Diacronia e Historia, Madrid, Gredos, 1978, $3^{\text {a }}$ ed.; Croft, op. cit.

${ }^{17}$ Concepción Company, «Grammaticalization and category weakness", en I. Wischer y G. Diewald (eds.), New reflections on grammaticalization, Amsterdam/Philadelphia, John Benjamins, 2002, págs. 201-215. 
ha puesto de relieve que es en la zona de contacto entre la sintaxis y el discurso donde se producen y comienzan su gestación los cambios lingüísticos: la gramática no es sino la fijación o codificación lingüística de determinadas estrategias discursivas ${ }^{18}$. Entre los factores que se asocian con la aparición de nuevos significados lingüísticos cabe destacar, según Heine ${ }^{19}$, los siguientes:

15) a. El contexto

b. La frecuencia de uso

c. Posibilidad de reinterpretación semántica por inferencia pragmática

d. Mecanismos de transferencia conceptual (metáfora, metonimia)

e. Direccionalidad (Abstraccion / Concrecion)

f. Consecuencias semánticas ('bleaching', generalización)

Dado que la gramaticalización es un proceso gradual, la tarea del lingüista consiste en desentrañar el proceso de difusión subsiguiente a toda innovación. Los factores de (15a) y (15b) intervienen de forma decisiva en los inicios del cambio linguístico. Trabajos recientes en la teoría de la gramaticalización coinciden en señalar que, más que sobre una pieza léxica concreta (p. ej. haber), los procesos de gramaticalización operan sobre construcciones o enunciados linguísticos en contextos (15a) discursivos reales: es la construcción entera, y no únicamente una pieza léxica particular, la que se ve sometida a gramaticalización ${ }^{20}$. El factor frecuencia (15b) ocupa hoy un lugar central en la teoría de la gramaticalización. La frecuencia está directamente relacionada con el resto de los factores de (15): una mayor frecuencia de uso conlleva un debilitamiento del significado debido a la rutinización del uso, posibilita la extensión de una construcción a nuevos contextos y, por último, potencia las posibilidades de que se produzca un cambio semántico en la construcción de partida ${ }^{21}$. Cuanta mayor frecuencia de uso alcance una construcción particular, más posibilidades habrá de que los hablantes reinterpreten esta secuencia con un significado unitario y no meramente composicional, a partir de los significados particulares de las piezas léxicas que forman la construcción ${ }^{22}$. Numerosos es-

${ }^{18}$ C. Company, «QQué es un cambio lingǘrstico?», en F. Colombo y M. A. Soler (eds.), Cambio lingǘstico y normatividad, México, UNAM, 2003, págs. 13-32 y «Grammaticalization and category weakness», art. cit; Elisabeth C. Traugott, «Constructions in Grammaticalization», en B. Joseph y D. Janda (eds.), The Handbook of Historical Linguistics, Oxford, Blackwell, 2003, págs. 624-647.

19 Bernd Heine, «On the role of context in grammaticalization», en I. Wischer y G. Diewald (eds.), New reflections on grammaticalization, op. cit., págs. 83-101 (pág. 84).

${ }^{20}$ Heine, art. cit.; Traugott, art, cit.; Joan L. Bybee, «Mechanisms of Change in Grammaticization: The Role of Frequency", en B. Joseph y R. D. Janda (eds.), The Handbook of Historical Linguistics, op. cit., págs. 602-623 (pág. 602).

21 Bybee «Mechanisms of Change in Grammaticization", art. cit., Hopper y Traugott op. cit. págs. 126-130; Company, «Qué es un cambio linguístico?», art. cit.

22 John Haiman, «Ritualization and the Development of Language», en W. Pagliuca (ed.), Perspectives on Grammaticalization, Amsterdam/Philadelphia, John Benjamins, 1994, págs 3-28. 
tudios han corroborado que frecuencia de uso y gramaticalización van de la mano: la segunda ocurre en aquellos contextos donde la primera es más elevada. En efecto, no basta con documentar una innovación para asegurar que nos encontramos ante un cambio lingüístico: «The innovations must be reinforced by use in order to become part of the mental knowledge of a speaken ${ }^{23}$. La frecuencia, por último, contribuye a un progresivo proceso de abstracción de la construcción de partida (15e) y al debilitamiento del significado referencial de las unidades léxicas (15f).

En cuanto al proceso de difusión en sí, es bien sabido que algunos fenómenos gramaticales se extienden de forma gradual a lo largo del lexicón: no todas las piezas léxicas se ven afectadas al mismo tiempo o con la misma frecuencia por un cambio linguístico. Como apunta $\mathrm{Croft}^{24}$ sreplication of a sintactic construction requires replication of its component lexical items», lo cual nos indica que el cambio lingüístiço parece seguir un modelo de difusión léxica. Este proceso de difusión consiste en la extensión de la nueva estructura a todos (o gran parte) de los contextos posibles ${ }^{25}$. De nuevo, este fenómeno de extensión parece estar orientado léxicamente y opera a través de conexiones semánticas y mecanismos de transferencia conceptual (15d) entre piezas léxicas estrechamente relacionadas, que generalmente conforman un espacio conceptual 0 dominio semántico común ${ }^{26}$.

Aunque la teoría de la gramaticalización ha constatado la importancia de los factores de (15), no se han aplicado, hasta donde se me alcanza, análisis de este tipo a las etapas iniciales de la gramaticalización de haber + pp. Por ello, me propongo presentar una propuesta que permita avanzar hacia la reconstrucción del proceso de gramaticalización y la difusión de los TA de acuerdo con los principios teóricos que acabo de esbozar, puesto que, como trataré de poner de manifiesto, su aplicación nos permitirá establecer con más precisión que en trabajos anteriores los cauces concretos de gramaticalización de haber + pp en español antiguo.

\section{EL CORPUS}

Uno de los primeros problemas a los que hemos de enfrentarnos al trazar las etapas iniciales de la gramaticalización de haber + pp radica en la ausencia de datos más antiguos que el Poema de Mio Cid: hasta donde se me alcanza,

\footnotetext{
${ }^{23}$ Croft, op. cit., pág. 186.

${ }^{24}$ Op. cit., pág. 33.

${ }^{25}$ Harris y Campbell, op. cit., págs. 97 y 106-119. El capítulo 5 de su libro constituye una buena aproximación a los procesos de difusión léxica que operan en algunos cambios sintácticos (especialmente las págs. 106-115).

${ }^{26}$ Croft, op. cit., pág. 154.
} 
ningún estudio previo sobre los TA ha manejado documentación anterior a los años finales del siglo XII, que es cuando podemos fechar los primeros textos literarios escritos en romance ${ }^{27}$. Este hecho nos coloca frente a un problema empírico considerable, puesto que el período del romance primitivo es justamente la etapa cronológica más interesante para observar los inicios de la gramaticalización de haber + pp. Por ello, he creído conveniente basar mi estudio en un corpus de documentos notariales que abarca los siglos IX al XIII (solo hasta 1250) y que comprende 2206 documentos en total, en los que únicamente he encontrado 59 casos de haber + pp. Estos documentos, redactados en latín y en romance, constituyen un corpus homogéneo tanto desde el punto de vista cronológico como diatópico, y tienen la ventaja de pertenecer a una misma tradición textual o género discursivo. La mayor parte de los documentos proceden de la Castilla centro-oriental: son la Colección diplomática de San Salvador de Oña ${ }^{28}$, el Cartulario de San Millán de la Cogolla ${ }^{29}, \operatorname{los}$ Documentos lingüisticos de España recopilados por Menéndez Pidal ${ }^{30}$ y una serie de documentos emilianenses del siglo XIII, editados por los hermanos García Turza ${ }^{31}$. También he examinado dos colecciones documentales leonesas (la del

${ }^{27}$ El extenso e influyente trabajo de Thielmann, art. cit, salvo un ejemplo de Valerio del Bierzo, no hace ninguna referencia al latín de Hispania. Por lo tanto, nada sabemos de la evolución de haber + pp en territorio peninsular desde la época visigoda hasta la aparición del PMC, si exceptuamos el breve apartado que Joan Bastardas, Particularidades sintácticas del latín medieval (Cartularios españoles de los s. VII al XI), Barcelona, CSIC, 1953 dedica a habere + pp, construcción de la que cita apenas 20 casos (pág. 140). Lamentablemente, sus datos no han sido apreciados por los investigadores posteriores, excepción hecha de Daniel Jacob, «¿Representatividad lingüística o autonomfa pragmática del texto antiguo? El ejemplo del pasado compuesto», en D. Jacob y J. Kabatek, (eds.), Lengua medieval y tradiciones discursivas en la Peninsula Iberica, Frankfurt, Vervuert/Lingüística iberoamericana, págs. 153-176 (págs. 162-63).

${ }^{28}$ Oñ = J. del Álamo, Colección diplomática de San Salvador de Oña (822-1284), Madrid, CSIC, 1950. En total, 339 docs., 2 del s. $\mathrm{XX}, 4$ del s. X, 61 del s. XI, 137 del s. XIl y 135 del s. XIII. Hasta el siglo XII todos los diplomas están redactados en latín, pero en el XIII tenemos 36 docs. escritos en romance y 99 en latin. He eliminado los docs. 36, 113, 190, 348, 371 y 396, por carecer de elementos de validación.

${ }^{29} \mathrm{Ub}=$ A. Ubieto Arteta, Cartulario de San Millán de la Cogolla 759-1076, Valencia, Anúbar, 1976. Son en total 437 documentos, 16 del s. IX, 99 s. X, 322 s. XI. No he considerado el doc. 231 aquí, sino en DLE, donde aparece también publicado (doc. 71) y Led $=$ M. L. Ledesma, Cartulario de San Millán de la Cogolla 1076-1200, Zaragoza, Textos medievales 80, 1989. Son en total 481 docs., 281 del s. XI y 200 del s. XII (descarto los documentos $482-512$ por carecer de fecha), todos en latín.

${ }^{30} \mathrm{DLE}=\mathrm{R}$. Menéndez Pidal, Documentos lingürsticos de España I: Reino de Castilla, Madrid, CSIC, 1966, reimp. de la ed. de 1919. Son en total 215 docs., todos en romance: 1 del XI, 43 del s. XIf, 171 del s. XuII. Contabilizo el doc. 91 de Pidal en Emil, por ser la transcripción más completa, y no aquí. No consideraré el ejemplo 275 , de 1225 , «t abet ferido in ista carta ubi dicitur meis, $\tau$ super scripto nostris", por ser una corrección posterior sobre el documento, de fecha y mano incierta.

31 Emil = Claudio y Javier García Turza, Una nueva visión de la lengua de Berceo a la luz de la documentación emilianense del siglo XIII, Logroño, Univ, de la Rioja, 1996. Son en total 
monasterio de Santa María de Carbajal ${ }^{32}$ y la del monasterio de Trianos ${ }^{33}$ ), y una de la zona aragonesa (los Documentos para el estudio de la reconquista y repoblación del valle del Ebro ${ }^{34}$ ).

No he tenido en cuenta, obviamente, ni los documentos en regesta ni los pontificios, por lo que los cómputos que ofrezco del número total de documentos para cada fuente están ya calculados sin la presencia de este tipo de documentos. Además, he eliminado aquellos documentos considerados como no válidos, de acuerdo con los criterios del editor de cada colección diplomática. A lo largo de este artículo, registro todos los ejemplos que aparecen de haber + pp (en los que el participio funciona como un predicativo), salvo cuando se trata de las fórmulas ratum habere 'dar por válido, confirmar' y habere concesum atque firmatum 'tener concedido', que aparecen algunas veces, ya que constituyen expresiones jurídicas formulaicas que siempre indican valor estativo. Una última precisión sobre la elección del corpus: algunos autores consideran que los documentos notariales son una fuente poco adecuada para el estudio de la sintaxis histórica, ya que se les achaca un alto grado de formulismo y cierta pobreza sintáctica. No obstante, el hecho es que la única fuente documental de la que disponemos para reconstruir la evolución de haber + pp en fecha anterior al siglo XIII son los documentos notariales y, por lo menos para el fenómeno que nos ocupa, creo que resultan sumamente interesantes ${ }^{35}$. La tabla 3 agrupa todos los ejemplos encontrados ordenados por tiempos verbales, indicando la frecuencia de aparición por siglos y el número de documentos del corpus, ordenados también por siglos. La tabla 4 recoge los ejemplos encontrados en el corpus $\mathbf{B}$.

53 documentos, todos ellos del siglo $\mathrm{Xm}$, escritos en romance. No consideraré como ejemplo $e$ algunos de ellos que auien, conprando, amatado pecho (47, 1237), porque García Turza lee con comas, y Menendez Pidal (DLE 91) sin ellas: ante la duda, he preferido dejar este caso en cuarentena.

${ }^{32}$ Carb = S. Dornínguez Sánchez, Colección documental del monasterio de Santa Maria de Carbajal (1093-1461), León, Centro de estudios e investigación "San Isidoro", 2000. En total, 146 documentos: 1 del s. XI, 56 del s. XII, 89 del s. XIII. Hay 37 docs. en romance, todos del s. XIII. He descartado los docs. $1,13,17,18,22,46,55$ y 170, por carecer de elementos de validación.

${ }^{33}$ Triar = J. de la Fuente Crespo, Colección documental del monasterio de Trianos (11111520), León, Centro de estudios e investigación «San Isidoro», 2000. Son en total 139 docs., 62 del s. XII y 77 del s. XII.

${ }^{34} \mathrm{Lac}=\mathrm{J}$. M. Lacarra, Documentos para el estudio de la reconquista y repoblación del valle del Ebro, Zaragoza, Textos Medievales 62, 1982, vol. I; J. M. Lacarra, Documentos para el estudio de la reconquista y repoblación del valle del Ebro, Zaragoza, Textos Medievales 62 , 1985, vol. II. Son en total 396 docs., 17 del s. XI, 378 del s. XII y 1 del s. XII; escritos todos en latín. He descartado los documentos $40,424,426,427,428,429,430,431,432$ y 433 porque carecen de fecha.

${ }^{35}$ Permítaseme poner en duda su supuesta invalidez para la reconstrucción sintáctica, al menos en lo relativo a los TA. Si son tan formulaicos, ¿cómo se explica que en un mismo período -el siglo XIV- los DLE muestren solo 16 ejemplos (en 42 documentos) mientras que en $\mathrm{T}$. Navarro Tomás, Documentos lingüísticos del Alto Aragón, Syracusse, Syracusse Univ. Press, 1957, aparecen 85 ejemplos (jmás del quíntuple!) en 57 documentos del mismo siglo XIv? 
TABLA 3

Frecuencias de haber + pp en el Corpus A

\begin{tabular}{|c|c|c|c|c|c|c|c|c|c|}
\hline Siglo & Dacumentos & $\mathrm{He}+\boldsymbol{P P}$ & $\begin{array}{c}\text { Habia } \\
P P\end{array}$ & $\begin{array}{c}\text { Fube + } \\
P P\end{array}$ & Haja + PP & $\begin{array}{c}\text { Bubiena + } \\
P P\end{array}$ & $\begin{array}{c}\text { Hubiese + } \\
P p P\end{array}$ & $\begin{array}{c}\text { Hubiere + } \\
P P\end{array}$ & Total \\
\hline$I X$ & 18 & 0 & 0 & 0 & 0 & 0 & 0 & 0 & 0 \\
\hline$X$ & 103 & 0 & 0 & 1 & 0 & 0 & 0 & 0 & 1 \\
\hline$X I$ & 683 & 2 & 0 & 10 & 2 & 0 & 1 & 0 & 15 \\
\hline$X I I$ & 876 & 12 & 2 & 3 & 0 & 1 & 0 & 1 & 19 \\
\hline$X I I I$ & 526 & 9 & 8 & 3 & 3 & 0 & 1 & 0 & 24 \\
\hline Total & 2206 & 23 & 10 & 17 & 5 & 1 & 2 & 1 & 59 \\
\hline
\end{tabular}

TABLA 4

Frecuencias de haber + pp en el Corpus B

\begin{tabular}{|c|c|c|c|c|c|c|c|c|c|c|c|}
\hline Obra & $H e+P p$ & $\begin{array}{c}\text { Habra } \\
P P\end{array}$ & $\begin{array}{c}\text { Hubse + } \\
\text { Pp }\end{array}$ & $\begin{array}{c}\text { Hayya }+ \\
P P\end{array}$ & $\begin{array}{c}\text { Hubiera } \\
+P P\end{array}$ & $\begin{array}{l}\text { Hubiese } \\
+P P\end{array}$ & $\begin{array}{l}\text { Hubliere } \\
+P P\end{array}$ & $\begin{array}{c}\text { Habra } \\
+P P\end{array}$ & $\begin{array}{c}\text { Haber } \\
p p\end{array}$ & $\begin{array}{c}\text { Habee + } \\
P P\end{array}$ & Torat \\
\hline$P M C$ & 146 & 18 & 10 & 2 & 0 & 0 & 0 & 1 & 1 & 2 & 180 \\
\hline$L R$ & 1 & 11 & 1 & 0 & 0 & 0 & 0 & 0 & 0 & 0 & 13 \\
\hline$R A$ & 1 & 2 & 0 & 1 & 0 & 0 & 0 & 0 & 0 & 0 & 4 \\
\hline RONC & 1 & 0 & 0 & 0 & 0 & 0 & 0 & 0 & 0 & 0 & 1 \\
\hline TOTAL & 149 & 31 & 11 & 3 & 0 & 0 & 0 & 1 & 1 & 2 & 198 \\
\hline
\end{tabular}

\section{LA ADQUISICIÓN DE LA ANTERIORIDAD}

A partir de los datos obtenidos en la tabla 3, podemos observar la escasa frecuencia de uso de la estructura haber + pp en español antiguo (únicamente 59 casos en 2206 documentos), lo cual es un dato sumamente significativo, puesto que la evidencia negativa en cambio lingüístico es una evidencia tan valiosa (a veces incluso más) como la positiva para interpretar los procesos de cambio. La distribución cronologica de la perífrasis muestra un proceso de generalización muy lento. Los textos literarios (Corpus B, tabla 4) muestran una mayor frecuencia de uso (también son de fecha más tardía que la mayoría de los documentos notariales que he utilizado), particularmente el Poema de Mio Cid. No obstante, hay que hacer ciertas matizaciones a las frecuencias absolutas obtenidas. En primer lugar, no todos los ejemplos encontrados son claramente TA puesto que, como es lógico, en el corpus se documentan ejemplos de resultativas tipo I que no permiten el reanálisis ni dan lugar a cambio semántico alguno (16-18).

16) Tovia $\tau$ Cogga femper .I. defefa outeron; $\tau$ illa rate de uillar, Uilla Gundiffaluo et Cordouin nonna outeron defefata de pafcere (DLE 71, 1044) '[los de] Villa Gundisalvo y Cordovin no tenían vetada la dehesa para pastar' ${ }^{36}$.

36 Pienso que defesata corresponde al verbo defender 'prohibir' más que al verbo defesar "hacer dehesa un terreno'; cf. el ejemplo (103) que aparece en el mismo documento. 
17) Estos sobre dichos molinos damos por heredamiento a sancta Maria de la Foz por a siempre, que los ayan quitos $\tau$ pagados (DLE 250, 1220)

18) Siveque concedimus ecclessie Sancti Michaelis de Petroso illam consuetudinem quam habuerunt antiquitus constitutam a parentibus nostris regibus in cedencis lignis in montibus de Auca et de Puras (Led 379, 1142) 'Concedemos...aquel uso que tenían establecido desde antiguo'.

Por otra parte, también el modo y el tiempo verbal en el que se encuentra flexionado el auxiliar haber tienen repercusiones a la hora de determinar la interpretación (resultativa o TA) de los ejemplos documentados. Los ejemplos que más se acercan a la lectura temporal son aquellos con el auxiliar flexionado en presente o imperfecto de indicativo y, particularmente, los pertenecientes a los tipos verbales que muestran mayor frecuencia de uso. Por el contrario, las formas imperativas, subjuntivas y los casos de habui + pp se muestran más reacios a aceptar lecturas de anterioridad. En concreto, los ejemplos en modo imperativo no admiten otra lectura que la resultativa (19 a-b); de los problemas que plantean las formas subjuntivas nos ocuparemos más adelante (\$ 4.3).

19) a. Honores $\tau$ tierras auellas condonadas 'tenedlas condonadas' (PMC 887)

b. Yo uos la fuelta $\tau$ auello quitado 'tenedlo quitado (quito)' (PMC 496)

En cuanto al pretérito anterior ${ }^{37}$, es un dato muy significativo el radical descenso de uso que experimenta esta forma en el tránsito del siglo XI al XII (Tabla 3) y la escasa frecuencia con la que aparece usado en los textos literarios (Tabla 4). Este hecho no solo parece indicar la escasa integración de esta forma en el incipiente paradigma de los TA (la forma hube + pp ha desaparecido hoy totalmente de la lengua oral, y es muy poco frecuente en el uso escrito) sino que muestra, además, que estas construcciones (20) pertenecían más bien a un estado lingüístico muy anterior, puesto que se relacionan mejor con el primigenio valor resultativo que con el naciente significado de TA.

20) illum malleolum que senior Azenari Sanchiz miserat per sua anima ad predictum sanctum in villa Formella et pater meus Garsea rex (...) a parte Sancti Emiliani abuit extraniatum (Ub 291, 1055); illas suas casas, quas ego per cartam habui ei datas in villam supradictam (Ub 368, 1068); et abti comparato illo solare de Alvaro Alvarez (Ub 379, 1070); Illam hereditatem de Villavizana habui eam datam ad domno Munnio de Marthia cum fideiussores (Led 60 1083); Alia vinea que dedit Gudumeri Furtum de Rivo, et habuit comparata de Gudumeri de Erbella in quatuor solidos (Led 196, 1090)

En castellano antiguo, la interpretación temporal de ove + pp se restringe casi exclusivamente a cláusulas subordinadas introducidas por conjunciones

${ }^{37}$ Un estudio sobre el uso de esta forma verbal a lo largo de la edad media puede encontrarse en el articulo de Silvia Hurtado González, «El pretérito anterior en castellano medieval», Verba, 27, 2000, págs. 205-221. 
temporales (quando, desque), mientras que en nuestro corpus de documentos notariales (Corpus A) esta forma verbal nunca aparece en este tipo de contextos, sino que lo hace en oraciones principales sin el apoyo de conjunciones temporales, lo que dificulta su interpretación como TA. Podemos observar esta diferencia en (21-22): los ejemplos de (22) se inclinan por la lectura temporal, gracias al refuerzo de la conjunción temporal quando; por el contrario, los de (21), que carecen de dicha conjunción, parecen aceptar con más dificultad la lectura de anterioridad: ovo bastidos equivale más bien a 'los abasteció' o 'los tuvo abastecidos' que a 'Ios hubo abastecido'. Muchos de los ejemplos antiguos ove + pp $(20,21)$ se acomodan mejor a la lectura como simples pretéritos 'y ganamos esta tierra de dona Estrucia' o como resultativos 'mantuvimos esta tierra ganada' (23) que a la interpretación temporal de anterioridad.

21) a. Ut donaremus (...) ipsas vineas suprascriptas nostras simul et suas quas ille abuit comparatas que sunt totas in territorio de Basconiolos (Oñ 31, 1045)

b. De todo conducho bien los ouo baftidos (PMC 68)

22) a. Quando ouo regnado Ezechias xiiii annos (LR 4, 23)

b. Todos fon adobados quando myo Çid efto ouo fablado (PMC 1000)

23) Et habuimus istam terram ganadam de domna Estruçia de Salçe et iaçe ista terra, latus el arroyo que exiit de villa (Oñ 124, 1106)

Una vez hechas estas puntualizaciones, procederé a caracterizar la muestra y a plantear las principales hipótesis de trabajo que voy a utilizar. La evolución y difusión de haber + pp en español antiguo puede explicarse a partir de dos hipotesis principales, que sitúan el tipo de participio y sus propiedades léxicas en el eje central de la discusión:

i) Hipótesis transitiva: la adquisición de valores temporales por parte de haber + pp comenzó en cláusulas con alto grado de transitividad; a medida que aumenta el grado de transitividad, aumenta también la interpretación de haber + pp como TA.

ii) Hipótesis de difusión léxica: la adquisición de valores temporales por parte de haber + pp fue un fenómeno que se extendió de forma gradual a lo largo del lexicón y que posiblemente se originó en los participios de los verbos relacionados con la posesión (dar, donar, comprar, dejar) y se extendió por difusión léxica a otros dominios semánticos afines - verbos de comunicación (decir, hablar), verbos de acción (hacer) y verbos transitivos de movimiento/ dirección (enviar, meter, sacar)- a través de los principales mecanismos de cambio semántico: a) transferencia metafórica b) abstracción conceptual c) extensión y generalización semántica ${ }^{38}$.

3s Una muy buena exposición de estos mecanismos se encuentra en el cap. 8 de Bybee, Perkins y Pagliuca, op. cit. Vid. además Hopper y Traugott, op. cit., y Heine, art. cit. 
Una de las ideas actuales más importantes sobre el concepto de transitividad es que ésta no es una propiedad intrínseca del verbo, sino que es más bien una propiedad de los predicados verbales. La transitividad es una noción que afecta a la organización de la frase, ya que relaciona el verbo y los demás constituyentes de la oración; supone una cohesion entre estos elementos establecida a través de la sintaxis de rección. Por tanto, es un fenómeno global, que recorre los niveles léxico, sintáctico y semántico y, a su vez, es un fenómeno gradual, porque se puede descomponer en una serie de propiedades mínimas.

Givón ${ }^{39}$ describe semánticamente un evento transitivo prototípico atendiendo a tres parámetros: «a. Agentivity: Having a deliberate, active agent b. Affectedness: Having a concrete, affected patient $c$. Perfectivity: Involving a bounded, terminated, fast-changing event in real time». Sintácticamente, evento transitivo es aquel que tiene un objeto directo. La transitividad relaciona al menos diez características de los predicados, pudiéndose establecer una escala de transitividad ${ }^{40}$ :

$\begin{array}{lll}\text { 24) } & \text { Alta } & \text { Baja } \\ \text { A. Participantes } & 2 & 1 \\ \text { B. Quinesis } & \text { acción } & \text { no acción } \\ \text { C. Aspecto } & \text { télico } & \text { atélico } \\ \text { D. Puntualidad } & \text { puntual } & \text { no puntual } \\ \text { E. Volicionalidad } & \text { volicional } & \text { no volicional } \\ \text { F. Polaridad } & \text { afirmativa } & \text { negativa } \\ \text { G. Modo } & \text { real } & \text { irreal } \\ \text { H. Agentividad } & \text { A aitamente agentivo } & \text { A escasamente agentivo } \\ \text { I. Afección del objeto } & \text { O afectado } & \text { O no afectado } \\ \text { J. Individuación del objeto } & \text { O altamente individualiz. O no individualizado }\end{array}$

Estos diez parámetros pueden agruparse en cuatro grandes grupos, según hagan referencia al Sujeto (E, H), al Objeto (A, I, J), a la Aspectualidad (B, C, D), a la Modalidad (G) y a la Polaridad (F). Mi hipótesis predice que, en igualdad de condiciones, las construcciones de haber + pp que tienen verbos de mayor transitividad se inclinan por lecturas más temporales (o menos resultativas), mientras que las que tienen verbos de mayor transitividad mantienen mejor su lectura resultativa:

25) a. Agora las ayan quitas heredades de Carrion (PMC 3715)

b. Amiba alço Colada, vn grant colpe dadol a (PMC 2421)

El ejemplo (25a) muestra un grado de transitividad bajo: aspectualmente, el participio quitas se define como un predicado estativo, durativo y no puntual,

\footnotetext{
${ }^{39}$ Op. cit., pág. 109.

40 Según el trabajo, ya clásico, de Paul J. Hopper y Sandra A. Thompson, «Transitivity in grammar and discourse», Language, 56/2, 1980, págs. 251-299.
} 
el sujeto presenta escasa agentividad, ya que es un tema y no un agente, el auxiliar en subjuntivo se relaciona con la modalidad irreal (porque aún no tienen quitas las heredades) y no denota un hecho factual, real. Sin embargo, (25b) es un predicado altamente transitivo: dar es un verbo causativo que denota una acción puntual, el sujeto de dar ejerce un control máximo sobre la acción y tiene carácter agentivo; que el modo del verbo sea el indicativo asegura que la acción expresada por el participio ha tenido lugar, que ha habido un paso o transición de la acción desde el sujeto al objeto. Sin lugar a dudas, el ejemplo más transitivo (25b) es un TA, el menos transitivo (25a), una construcción resultativa.

Aunque no todos los casos son tan claros como este, podemos predecir en gran medida la interpretación de un ejemplo dado a partir de la escala de transitividad: como trataré de mostrar, la dirección que siguió el proceso de gramaticalización de haber + pp como un TA se halla condicionada por los factores (A-F) involucrados en dicha escala.

\subsection{Factores relativos al sujeto $(E, H)$}

Que exista correferencia sintáctica entre el sujeto de haber y el sujeto del participio constituye uno de los factores decisivos para poder interpretar esta secuencia como TA, tal y como han señalado diversos estudios ${ }^{41}$. No obstante, si la correferencia sintáctica viene acompañada de correferencia semántica (esto es, que ambos sujetos reciban el mismo papel temático) y particularmente, si esta correferencia marca el argumento que se proyecta como Sujeto con el papel temático de agente, en ese caso, las posibilidades de interpretar la secuencia haber + pp como un TA aumentan. Consideremos los siguientes ejemplos:

26) a. Delo que auien fecho mucho repifos fon (PMC 3569)

b. Non tiene en cuenta los moros que ha matados (PMC 1795)

27) a. Ya don Rachel $\tau$ Vidas, auedes me olbidado (PMC 155)

b. Dixo el Rey don Alfonffo: «mucho me auedes en bargado» (PMC 2147)

En (26 a-b) los sujetos tienen carácter agentivo $(\mathrm{H})$, ya que presentan control y volición (E) sobre el evento denotado por el verbo, por lo que favorecen la lectura temporal de avien fecho y ha matados como 'están muy arrepentidos de lo que han hecho' y 'no tiene en cuenta los moros que ha matado'. Por el contrario, en (27 a-b) los sujetos presentan un grado de control escaso (porque en estos ejemplos, olvidar y embargar son acciones que no suceden debido a una intención expresa del sujeto) y parecen aceptar mejor la lectura resultativa (donde el sujeto sería un experimentante) ' ¡Ya don Rachel y Vidas, me tenéis olvidado!', 'Dijo el Rey: me tienes muy embargado' que la lectura temporal.

\footnotetext{
${ }^{41}$ Pínkster, art. cit., pág. 201; Vincent, art. cit., págs. 79-85; Lapesa, op. cit., pág. 781.
} 
La identidad de agentes, además, supone la invalidación del cambio de diátesis, una de las características que definen a los tiempos anteriores frente a los resultativos (II). Agentividad $(\mathrm{H})$ y Volición $(\mathrm{E})$ son dos factores estrechamente ligados, puesto que es difícil imaginar un participante que sea volitivo y no agente, o a la inversa. El prototipo de agente volitivo es un sujeto humano. Nuestros datos muestran una restricción en el carácter referencial del sujeto, ya que el $96,61 \%$ (Corpus A) y el $95,95 \%$ (Corpus B) de los sujetos son sujetos personales ${ }^{42}$. Esta restricción distingue a los primeros ejemplos romances de haber + pp de sus homólogos en latín, lengua en la que no parece haber restricciones sobre el carácter referencial del sujeto ${ }^{43}$. El carácter no personal del sujeto dificulta la lectura temporal (por lo general, en los ejemplos más antiguos los casos con sujetos no personales son siempre construcciones resultativas), como se desprende de los ejemplos de (28): mientras que (28a), que presenta un sujeto no personal 'petalum', no admite otra lectura que la resultativa (* el petalum habia escrito' el nombre de Dios...), (28b) puede admitir tanto la interpretación resultativa "lo encontraréis escrito en aquel volumen de cartas que tenemos selladas en nuestra iglesia' como la temporal 'lo encontrareis escrito en aquel volumen de cartas que hemos sellado en nuestra iglesia': el carácter personal del sujeto hace posible la doble lectura ${ }^{44}$.

28) a. Petalum aurea lammina in fronte pontificis quae nomen Dei tetragrammaton Hebraicis litteris habebat scriptum (S. Isid. Etym. 19, 21, 7) 'el petalum era una lámina de oro colocada en la frente del pontífice que tenía escrito el tetragrammaton, el nombre de Dios, en letras hebreas'

b. exemplar litterarum cuius quas in nostra ecclesia signatas habemus in subscripta pagina scriptum invenietìs (Lac 54, 1118)

Con todo, la agentividad y el carácter personal del sujeto no son por sí solos requisitos suficientes para explicar el cambio Resultativo > TA, ya que la agentividad no es incompatible con las estructuras resultativas: tanto en español como en otras lenguas existen construcciones resultativas con sujetos agentivos y personales que no son susceptibles de cambiar a TA (te tengo dicho que no hagas eso, tengo estudiada la lección).

\footnotetext{
${ }^{42}$ Los datos absolutos son $57 / 59$ para el Corpus A y $190 / 198$ para el Corpus B. Con todo, ило de los dos sujetos no personales que encontramos en el corpus A, el monasterio de Sancto Domingo de Silos (55), debe interpretarse como personal, ya que hace referencia al colectivo de personas, y no al edificio en sí. En cuanto al corpus B, tres de los ocho sujetos no personales que aparecen revisten un carácter netamente personal por personificación poética (el Agua y el Vino en RA 123 y 225, la espada Colada en PMC 3657).

43 Jacob, «A propos de la périphrase habeo + participe», art. cit. pág. 372. Basta solo fijarse en mis ejemplos (12 b-c), (13c) o, simplemente, consultar cualquier obra latina para notar esta diferencia. Por ejemplo, en las Etimologias de San Isidoro o en la Mulomedicina Chironis aparecen con mucha frecuencia sujetos de carácter no personal.

${ }^{44}$ Dado que nos encontramos frente a una construcción Resultativa tipo I, en este ejemplo considero preferible la lectura resultativa a la temporal.
} 


\subsection{Aspectualidad $(B, C, D)$}

En mi impresión, son los factores relacionados con la Aspectualidad los realmente decisivos en la adquisición de la categoría de la anterioridad. Si descartamos el factor (C), por cuanto todos los ejemplos encontrados, ya resultativos ya TA, son necesariamente télicos (alcanzan un límite) las diferencias en el grado de transitividad alcanzado deberían encontrarse en los parámetros Puntualidad (B) y Quinesis (D), que hacen referencia al tipo de evento denotado por el verbo.

Consideremos la clasificación de los eventos en estados, procesos (divididos en télicos y atélicos) y acciones (que pueden ser télicas o atélicas) ${ }^{45}$. Los estados son eventos estáticos que denotan la situación en que se encuentra un individuo o las propiedades del mismo. Los procesos son transiciones entre dos estados en los que se ve implicada una misma entidad, que padece o experimenta el acontecimiento señalado por el verbo. Las acciones son procesos controlados por un agente. La estructura interna de los estados es homogénea, puesto que el estado es el mismo en todas sus fases: no hay cambio ni progresión en el tiempo. Procesos y acciones se caracterizan como eventos dinámicos, frente a los estados, que se definen como no dinámicos o estáticos. Ambos implican un cambio o progreso a lo largo del intervalo de tiempo en que ocurren, por lo que su estructura interna no es homogénea, sino que está compuesta de diferentes fases. Existe una relación directa entre Aspectualidad y Agentividad. Los eventos que se caracterizan como acciones poseen prototípicamente sujetos agentivos cuya posición sintáctica es la de argumento externo, mientras que en los procesos y en los estados el sujeto suele ser un argumento interno que recibe un papel temático no agentivo. En definitiva, el tipo eventivo del predicado determina las propiedades y la configuración semántica del sujeto: en realidad, los factores $(\mathrm{E}, \mathrm{H})$ de la escala de transitividad están condicionados por (B).

Consideremos ahora la siguiente jerarquía que establece el grado de dinamicidad de una situación ${ }^{46}$ :

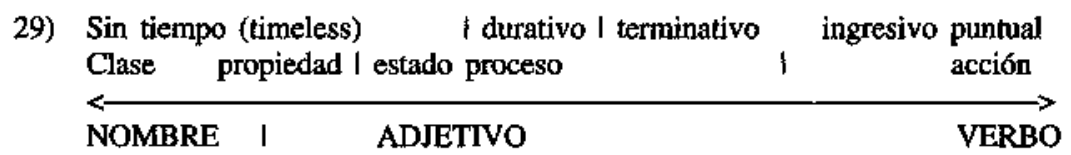

${ }^{45}$ Elena De Miguel, «El Aspecto Léxicom, en I. Bosque y V. Demonte (dirs.), Gramática descriptiva, op. cit., págs. 2977-3060. Givón, op. cit., pág. 106.

${ }^{46}$ Christian Lehmann, «Latin predicate classes from an onomasiological point of view», en DE VSV: Etudes de syntaxe latine offertes en homage d̀ Marius Lavency, D. Longrée (bd.), Leuven, Peeters, 1995, págs. 163 174 (pág. 172). 
Las construcciones resultativas están más cerca de las características de la categoría adjetivo que del verbo prototípico: expresan un estado alcanzado que se mantiene en el presente; en ellas, al igual que en los adjetivos, la idea temporal se halla debilitada, puesto que un estado es de por sí estable. Dado su carácter resultativo, las construcciones de (12), (13) y (14) operan en el esquema de derecha a izquierda, de la acción al resultado final. Algunas de estas construcciones incluso denotan una cualidad o propiedad del sujeto (12 b-c), lo cual las acerca todavía más a la categoría de los adjetivos. Únicamente los eventos caracterizados aspectualmente como acciones télicas (hacer la comida) o procesos télicos (ver un informe) pueden dar lugar a construcciones resultivas (la comida está hecha, tengo hecha la comida, tengo visto el informe).

La categońa verbal tiempo se halla mejor caracterizada en los eventos que denotan acciones que en los que denotan estados o procesos. Esto es así porque el tiempo es un concepto cambiante, dinámico; a medida que avanzamos hacia la derecha en la jerarquía, una situación dada se vuelve más dinámica y menos estable en el tiempo (time-stable), se acerca más al prototipo de verbo. El concepto de transitividad suele asociarse prototípicamente con el concepto de actividad o acción; acción que, ejercida por un individuo, pasa a ser transmitida a un objeto. De acuerdo con Givón ${ }^{47}$, «prototype verbs code rapid changes in either the state, condition or spatial location of some noun-code entity (...) They are coherent bundles of experience of relatively short duration». Verbo prototípico es, pues, aquel que expresa una acción, preferiblemente de carácter puntual o de corta duración.

Por tanto, cuanto más a la derecha en la gradación (29) podamos situar la construcción haber + pp, más posibilidades habrá de que esta exprese valor temporal. Para determinar la posición de la perífrasis en esta escala, el factor decisivo lo constituye el tipo de verbo que se combina con haber, esto es, el grado de transitividad que alcanza en relación a la Quinesis (B) y a la Puntualidad (D). Lo sorprendente es que, en semejante clasificación, mis ejemplos de haber + pp en los cartularios peninsulares difieren notablemente de los ejemplos documentados en latín clásico y latín tardío. Los siguientes cuadros recogen los tipos léxicos de participios documentados en los dos corpus que he utilizado, agrupados por dominios semánticos, y la frecuencia absoluta de aparición de cada verbo ${ }^{48}$ :

${ }^{47}$ Op. cit. pág. 52.

${ }^{48} \mathrm{Si}$ un participio aparece más de uлa vez, doy la forma masc. sg. como predeterminada. Si aparece solo una vez, doy la forma documentada. Recojo la forma latina únicamente cuando el participio aparece exclusivamente en documentos latinos; si hay casos en romance o en latín y romance, anoto por la forma romance. En el cómputo del PMC no he incluido los vv. 125, 174, $784,846,1043,1113,1789,2255,2423,2864,3053$ y 3372 , debido a los problemas filológicos que plantean. Cf. mi trabajo «la selección del auxiliar en el Poema del Mio Cid y otros textos medievales: cuestiones filológicas», de próxima publicación en Actas del XXIV CILPR. 
TABLA 5

Participios Corpus A

\begin{tabular}{|c|c|c|c|c|}
\hline $\begin{array}{c}\text { Posesión, adqudstición } \\
\text { y pérdidn (34) }\end{array}$ & $\begin{array}{c}\text { Comunicacion } y \\
\text { actos performatives ( } 8 \text { ) }\end{array}$ & Acción y realización (I3) & $\begin{array}{l}\text { Movimiento y } \\
\text { Dirección (3) }\end{array}$ & Otros (1) \\
\hline $\begin{array}{ll}\text { Dado (11) } & \text { Extraniatum (1) } \\
\text { Comprado (8) } & \text { Recibido (1) } \\
\text { Donado (4) } & \text { Prestado (1) } \\
\text { Accepaum (3) } & \text { Pagado (2) } \\
\text { Otorgado (1) } & \text { Ganado (1) } \\
\text { Laxatas (1) } & \end{array}$ & $\begin{array}{c}\text { Dicho (4) } \\
\text { Vetatum (2) } \\
\text { Obligada (1) } \\
\text { Defensado (1) }\end{array}$ & $\begin{array}{c}\text { Fecho (7) } \\
\text { Constitutam (1) } \\
\text { Complidos (1) } \\
\text { Creatum (1) } \\
\text { Completurn (1) } \\
\text { Vencido (1) } \\
\text { Signatas (1) }\end{array}$ & $\begin{array}{l}\text { Sacada (2) } \\
\text { Missas (1) }\end{array}$ & $\begin{array}{l}\text { Quito } \\
\text { (1) }\end{array}$ \\
\hline
\end{tabular}

TABLA 6

Participios Corpus B

\begin{tabular}{|c|c|c|c|c|}
\hline $\begin{array}{c}\text { Pasesión adquisición } \\
\text { y pentida (74) }\end{array}$ & $\begin{array}{c}\text { Comunicación y } \\
\text { actos performativas } 28 \mathrm{y}\end{array}$ & $\begin{array}{l}\text { Acción y } \\
\text { realización }\end{array}$ & $\begin{array}{l}\text { Acriwidad } \\
\text { Fistica (7) }\end{array}$ & $\begin{array}{l}\text { Activided } y \\
\text { reaction }\end{array}$ \\
\hline $\begin{array}{ll}\text { Dexado (11) } & \text { Tollido (2) } \\
\text { Ganado (I1) } & \text { Sueltas (2) } \\
\text { Dado (9) } & \text { Recabdado (1) } \\
\text { Preso (8) } & \text { Bastido (1) } \\
\text { Amancado (8) } & \text { Pagado (1) } \\
\text { Tomado (3) } & \text { Costado (1) } \\
\text { Otorgado (3) } & \text { Vendido (1) } \\
\text { Robado (3) } & \text { Cogido (1) } \\
\text { Perdido (4) } & \text { Tenido (1) } \\
\text { Conquista (2) } & \text { Cazado (1) }\end{array}$ & $\begin{array}{ll}\text { Dicho (8) } & \text { Rebtado (1) } \\
\text { Fablado (3) } & \text { Pedido (1) } \\
\text { Vedado (3) } & \text { Consejado (1) } \\
\text { Mandado (3) } & \text { Condonada (1) } \\
\text { Rogado (2) } & \text { Profetizado (1) } \\
\text { Echado (2) } & \text { Contado (1) } \\
\text { Jurado (I) } & \end{array}$ & $\begin{array}{l}\text { Fecho (20) } \\
\text { Acabado (3) } \\
\text { Vencido (3) } \\
\text { Cumplido (1) } \\
\text { Logrado (1) }\end{array}$ & $\begin{array}{c}\text { Matado (2) } \\
\text { Camtado (1) } \\
\text { Lidiado (1) } \\
\text { Cercado (1) } \\
\text { Ferida (1) } \\
\text { Buscar (1) }\end{array}$ & $\begin{array}{c}\text { Airado (3) } \\
\text { Sotaado (1) } \\
\text { Abiltado (1) } \\
\text { Escarmentado (1) } \\
\text { Honrado (1) } \\
\text { Embargado (1) } \\
\text { Oblidado (1) } \\
\text { Desfechos (1) }\end{array}$ \\
\hline $\begin{array}{l}\text { Movimiento y } \\
\text { Directión (I9) }\end{array}$ & Otros (23) & $\begin{array}{c}\text { Semanticamente } \\
\text { Impersonales } \\
\text { (3) }\end{array}$ & $\begin{array}{c}\text { Pencepción y } \\
\text { cognición } \\
\text { (I) }\end{array}$ & $\begin{array}{c}\text { Verbos } \\
\text { incousanivas } \\
\text { (4) }\end{array}$ \\
\hline $\begin{array}{ll}\text { Mandado 'enviar' (3) } \\
\text { Cabalgado (1) } & \\
\text { Passar (4) } & \text { Cortido (1) } \\
\text { Metida (3) } & \text { Buelto (1) } \\
\text { Llevada (1) } & \text { Enviado (2) } \\
\text { Sacada (1) } & \text { Tomados (1) } \\
\text { Poner (1) } & \end{array}$ & $\begin{array}{|ll|}\text { Parar (5) } & \text { Adobadas (1) } \\
\text { Casadas (3) } & \text { Servido (I) } \\
\text { Pablado (2) } & \text { Espesos (1) } \\
\text { Quebrado (2) } & \text { Reinado (1) } \\
\text { Estado (2) } & \text { Tajado (1) } \\
\text { Fincada (1) } & \text { Emponzotado (1) } \\
\text { Quito (2) } & \end{array}$ & $\begin{array}{c}\text { Passar (1) } \\
\text { Fallido (1) } \\
\text { Acreçido (1) }\end{array}$ & Asmado (1) & $\begin{array}{l}\text { Entrado (1) } \\
\text { Llegado (1) } \\
\text { Arribado (1) } \\
\text { Rastado (1) }\end{array}$ \\
\hline
\end{tabular}

La diferencia más notable respecto de la situación latina radica, sin duda, en la ausencia de verbos de percepción y conocimiento intelectual, como (14b), de los que únicamente documento un caso con asmado en el Poema de Mio Cid (PMC 844). Teniendo en cuenta este dato, considero que la hipótesis que sitúa los verbos de de percepción y conocimiento intelectual como contexto privilegiado de gramaticalización de la perífrasis debe ser revisada. El factor frecuencia (15b) es uno de los principales indicadores de cambio linguístico en marcha, si la frecuencia de uso de haber con verbos de percepción y conocimiento intelectual (según mis datos) es nula, difícilmente podemos atribuir a estos predicados el carácter de contexto privilegiado en la gramaticalización de haber + pp. Por otra parte, estos verbos presentan escasa agentividad (A), lo 
que les aleja del prototipo de verbo transitivo y, aunque suelen presentar correferencia explícita de sujetos, el sujeto de estas construcciones no es propiamente un agente, sino un experimentante ${ }^{49}$.

Otro dato sumamente interesante lo constituye el tipo de participio que se documenta con mayor frecuencia. Pese a tratarse de tradiciones textuales diferentes (documentos notariales en el caso del Corpus A, textos literarios de diversos géneros en el caso del Corpus B) ambos corpus muestran un grado de similitud sorprendente en los dominios semánticos que presentan más tipos de participios ${ }^{50}$. En principio, esta similitud parece indicar que la distribución léxica observada y la ausencia de participios de percepción y conocimiento intelectual se corresponden con factores gramaticales y no se ve alterada por factores estilísticos debido al tipo de texto utilizado.

¿Qué tienen en común los tres dominios semánticos (posesión, comunicación y acción) en torno a los çuales parecen agruparse la mayoría de los ejemplos? Tomemos un verbo representativo de cada dominio, atendiendo a la frecuencia de aparicion: dar, decir, hacer. En primer lugar, una característica que une a estos verbos es su carácter general y su alta frecuencia de lengua. Segundo, dar, decir y hacer son verbos prototípicamente transitivos, de uso intransitivo raro. Tercero, los tres verbos son archilexemas de sus respectivos campos semánticos, y se perfilan como los términos causativos dentro de sus correspondientes paradigmas léxicos. Cuarto, los verbos documentados pertenecen a dominios semánticos concretos y están relacionados entre sí mediante conexiones léxicas y paradigmáticas (particularmente densas y visibles en el dominio semántico de la posesión, que es también el que cuenta con el mayor número de ejemplos).

Como puede observarse, los datos muestran que en la etapa más antigua, haber + pp se relaciona únicamente con ciertas clases de verbos y que, progresivamente, se fue extendiendo a lo largo del lexicón hasta alcanzar la situación del español actual, lengua en la que es posible formar TA con cualquier tipo

49 Véanse las observaciones críticas de Jacob, «A propos de la periphrase habeo + participe», art. cit., págs. 374-75 y Detges, art. cit., págs. 352-54 sobre la hipótesis de los verbos de percepción y conocimiento intelectual como contextos originarios de reinterpretación de la perffrasis. En mi corpus aparecen numerosos ejemplos de verbos de percepción y cognición en otros tiempos verbales, pero nunca como TA. Es más, verbos como ver $\mathrm{u}$ oír aparecen constantemente, incluso en contextos de máxima relevancia presente (Dixieron los fieles: «esto oymos nos» (PMC 3692); En este dia mismo (...) desto son testigos que lo vieron et que lo oyeron (Oñ 494 1241), donde la referencia temporal en este dia mismo exigiría un antepresente en castellano actual).

So Evidentemente, los textos literarios muestran una mayor riqueza y variedad en los tipos léxicos de participios, pero lo que me interesa subrayar es la notabilísima semejanza de las cifras en los dominios semánticos: los cuatro dominios semánticos numéricamente más representativos (posesión, comunicación, acción y movimiento) son los mismos en ambos corpus. 
de verbo. Por ello, debemos concluir que la extensión de haber + pp fue un fenómeno gradual que se produjo mediante difusión léxica: como trataré de poner de manifiesto, afectó primero a los lexemas estrechamente relacionados con haber y, a partir de ahí, se fue extendiendo a otros dominios semánticos y clases verbales.

\subsubsection{Verbos de posesión, adquisición y pérdida}

En indoeuropeo no existía un verbo que correspondiera al significado del latín habere; de hecho, parece que el concepto de posesión es una adquisición tardía dentro de las lenguas indoeuropeas. Tipológicamente no es frecuente la existencia de un verbo 'haber' que indique posesión, ya que la mayor parte de las lenguas del mundo no lo conocen. Haber es un verbo de baja transitividad que se deriva históricamente de otros verbos transitivos que expresaban la noción de 'coger' o 'tomar', puesto que los significados de 'coger/tomar' y 'tener' forman una secuencia lexemática de términos no resultativo y resultativo: filius pecuniam capit -- filius pecuniam habet. Esta derivación consiste en una inferencia de tipo metonímico por la cual el resultado implícito de tomar posesión (esto es, tener posesión) se convierte en el significado principal del verbo ${ }^{51}$ :

30) Gramaticalización de *ghabh- 'coger' > habere «If one has taken possession, one has possession"

La noción de 'coger/tomar' es un gran foco de concentración e irradiación sinonímica, que provee la expresión no solo de 'tener', sino también la de 'dar'. Por todo ello, aunque únicamente es habere el verbo que expresa posesión, el dominio semántico de la posesión consiste en un sistema complejo de conexiones y redes léxicas que engloba la adquisición (coger, tomar, ganar), la transferencia (dar, donar, otorgar, pagar, prestar), la pérdida (dejar), la recepción (aceptar, recibir) y la posesión misma (haber, tener, poseer). Estas nociones forman un continuum que va desde la causatividad (dar $=$ hacer que otro tenga) hasta la estatividad (tener), tal y como se refleja en (31). Los verbos situados más a la izquierda son términos causativos, y por lo tanto, más transitivos ${ }^{52}$. Aspectualmente se definen como eventos dinámicos y agentivos,

s」 Givón, op. cit. pág. 134; Benjamín García Hernández, «Lexicología y semantica. En tomo a la noción de posesión en latín», en Actas del X Congreso Espafiol de Estudios Clásicos, A. Alvar Ezquerra y F. García Jurado (eds.), Madrid, Sociedad Española de Estudios Clásicos, 2001, vol. П. págs. 5-31 (págs. 21-25).

${ }^{52}$ El símbolo .- marca una relación intrasubjetiva de carácter diatético; $\cdots$, por el contrario, expresa rełación intrasubjetiva de carácter aspectual no-resultativo--resultativo. La pertinencia de estos campos semánticos y las relaciones paradigmáticas entre sus miembros integrantes ha sido comprobada en una larga nómina de trabajos: entre otros, B. García Hernández, Semántica estructural y lexemática del verbo, Reus, Avesta, 1980 y art. cit., Juan F. Domínguez Domínguez. 
pero a medida que avanzamos hacia la derecha, el nivel de agentividad, el grado de transitividad y el número de participantes decrecen:

31) + Causatividad/ + Transitividad - Causatividad/ - Transitividad

\begin{tabular}{lll}
\hline dar - (A da B a C) & recibir -- (C recibe B de A) & haber (C tiene B) \\
vender - (A vende B a C) & comprar -- (C compra B a A) & haber (C tiene B) \\
coger - (A coge B) & & haber (A tiene B) \\
quitar - (A quita B a C) & ganar -- (A gana B) & haber (A tiene B) \\
dejar - (A deja B) & & carecer (A no tiene B)
\end{tabular}

La reinterpretación de haber + pp como TA siguió el camino inverso a la gramaticalización de habere como verbo de posesión (30). Como hemos visto, el cambio semántico no opera in abstracto, sino que se origina en contextos deterninados $\mathrm{y}$, generalmente, se difunde a través de mecanismos de transferencia conceptual (metáfora, metonimia) entre dominios semánticos relacionados. Contemplada desde esta perspectiva, parece verosímil suponer que la reinterpretación de haber + pp se iniciara en los contextos más afines a este verbo: aquellos en los que intervenían otros verbos de su mismo dominio semántico. La mayor frecuencia de estos verbos en nuestro corpus es otro dato a favor de esta suposición: la alta frecuencia fija el uso, lo rutiniza y crea estabilidad paradigmática ${ }^{53}$.

Particularmente, es en los verbos que indican transferencia (causación de posesión) y pérdida (cesación de posesión) donde más posibilidades hay de que se produzca el cambio semántico hacia la anterioridad, mediante una inferencia de tipo metonímico que focaliza la parte causativa de la relación semántica de la posesión (dar, dejar) y no la parte estativa (haber). Primero, porque en el plano temporal la idea expresada por dar, donar o dejar es anterior a la de tener. Segundo, porque la misma idea de transferencia o de cesación de la posesión hace que el valor posesivo de haber se vea debilitado, y abre la posibilidad de reinterpretar este verbo como un auxiliar de tiempo: difícilmente podemos conceptualizar en términos de posesion lo que no se sigue poseyendo (te doy un libro = ya no lo tengo, por tanto *te tengo dado un libro). Puesto que los términos causativos de estas relaciones (dar, coger, etc...) son verbos muy transitivos y de Aktionsart puntual, su correspondiente acción resultativa no desemboca propiamente en haber + pp, sino en la simple posesión: haber 'tener'. La acción resultativa de dar no es propiamente 'tener dado', sino que

Lexemática latina. Estudio de los verbos de «encontrar*, Leon, Univ, de León, 1995, Antonio M. Martín Rodriguez, Los verbos de 'dar' en latin arcaico y clasico, Las Palmas, Univ. de Las Palmas, 1999 y Pamela B. Faber y Ricardo Mairal Uson, Constructing a Lexicon of English Verbs, Berlin/Nueva York, Mouton de Guyter, 1999.

53 Company, «Qué es un cambio lingüístico?», art. cit., págs. 28-29 y Bybee, «Mechanisms of Change in Grammaticizations, art. cit. 
es el verbo tener en sí el que expresa el resultado de dar: el resultado de le di el libro a mi padre es mi padre tiene el libro (que yo le he dado), no ?? mi padre tiene dado el libro o ?? tengo dado un libro a mi padre, estructuras de dudosa gramaticalidad en español. Consideremos los siguientes ejemplos donde interviene el verbo dar:

32) Dono et concedo supradictum Ospitali totum quantum ego ibi habeo datum et aliis hominibus, tam viris quam mulieribus, de tota mea terra, idest kastris (Lac 235,1134 )

33) E quanto que vos auemos dado assi como sobrascripto es, damos vos lo todo in helemosina (DLE 262, 1194)

34) Et post sex annos complitos ad Martorore, si abuero vobis datum vestro avere aut aliquis per me, quod redatis meo ortale (Lac 209, 1131)

35) Como to ouo dado donna Guisabel et encara meioro desend en aca (Emil 49, 1241)

36) el ospital nuestro d'Açofra, el qual ovo dado a Sant Millan donna Guisabel por su alma (Emil 49, 1241)

37) Et vos abbat don Peydro aviedes dados CC morabetinos a mio padre Dia Sanchez sobresta heredat (On 499, 1244)

38) Al Rey Fariz iij. colpes le auie dado (PMC 760)

39) Mucho preçia la ondra el Çid quel auedes dado (PMC 1848)

Creo que es preferible leer estos ejemplos como TA, puesto que las características del verbo dar, junto a la configuración semántica de la cláusula, excluyen la lectura resultativa tener dado. El verbo dar se define como «acción, transitiva, centrífuga, causativa de una posesión, con irrelevancia de la idea de movimiento», al tiempo que en el plano temporal la acción de dar es anterior a la de tener ${ }^{54}$. Por tanto, dar es semánticamente un verbo dinámico, y esa misma dinamicidad disminuye la posibilidad de interpretar estos ejemplos en clave resultativa. Otro tanto puede decirse para los ejemplos con donar (40-42), verbo que expresa una acción dativa caracterizada por una relación de especial interés del segundo actante para el tercero ${ }^{55}$. Aunque se ha señalado el carácter más puntual de do respecto a dono (semánticamente más durativo) la construcción tener donado resulta así mismo extraña al castellano.

40) Dono tibi totum ut sedeas inde abbate omnibus diebus vite tue et successoribus tuis excepto nullo foro malo, nisi quomodo illa populatione habeo donato (Lac 204,1131 )

54 Martín Rodríguez, op. cit., pág. 83.

${ }^{55}$ Martín Rodríguez, op. cit., pág. 218-21. Los restantes ejemplos que en el corpus A aparecen con dar y donar son los siguientes: nisi fuerit ibi causa quod ego aut pater meus cui sit requies abuissemus donato cum carta ad sanctos aut aliquo homine et dono et concedo hoc donativum super scriptum (On 111, 1099); Denique non est nobis dubium sed multis manet notissimum et cognitum et quod de nostro datum habuistis concessum atque firmatum tibi abati Enneconi cum omni collegio monacorum de Santi Salvatoris Onie $(O \bar{n} 40,1056)$; Idem. $(O \bar{n} 46$ 1063). Nótese que en estos dos últimos ejemplos datum habuistis es una subordinada relativa, mientras que concessum atque fimatum son participios predicativos de manet. 
41) Dono totum [...] extra illud quod ante abebat ibi donato meo germano cum carta ad caballeros et ego similiter post eum (Lac 21, 1105)

42) et de illas almunias de Alcolea in uso usque ad illa Palomera quomodo habeo donatos ad illa populatione de Afaiarin (Lac 204, 1131)

Los verbos de pérdida o abandono de posesión, como dejar (43-45) o perder (46-47) parecen inclinarse preferentemente por la lectura temporal. Como ya he explicado anteriormente, el carácter dinámico de estos verbos y la propia idea de carencia de posesión establecen unas condiciones idóneas para el cambio semántico hacia la anterioridad. Si nos fijamos, por ejemplo, en los ejemplos (45) y (47) podremos observar que ninguno de los dos casos admite la lectura resultativa: * tiene dejada a Huesca, * Hoy tengo perdido esfuerzo.

43) postquam illos xaricos moros fuerint itos vel andatos ad terras de moros et habuerint laxatas illas hereditates ad lure xaricos cristianos (Lac 183, 1129)

44) En grado uos lo tengo lo que me auedes dexado (PMC 1069)

45) E dexado a Hue(ca $\tau$ las tierras de Mont Aluan (PMC 1089)

46) E cobro toda la tierra que auia perdida so auuelo Roboam (LR 3,22)

47) Oje perdido effuerço con que folya ganare (RONC 43)

Dentro de los verbos de adquisición y ganancia, cuanto más causativos sean los verbos, más posibilidades existirán de leerlos en clave temporal, y viceversa. Dentro de los términos causativos, los ejemplos con arrancar, tomar, robar, hurtar o vender (48-52) parecen inclinarse mejor por la interpretación temporal porque, por un lado, son verbos dinámicos que denotan acciones puntuales $\mathrm{y}$, por otra parte, admiten con dificultad la lectura resultativa: * tienen robado el campo, * lo tienen tomado a prisión. Lo mismo sucede con el verbo comprar (53-57) que, aunque no es tan causativo como vender, presenta en todos los casos un sujeto agentivo y volitivo. En mis ejemplos, la interpretación temporal de comprar se ve favorecida además por la ausencia de concordancia en casi todos los casos (53-55).

48) Pocos dias ha, Rey, que vna lid a arrancado (PMC 1849)

49) Al conde don Remont a prefon lean tomado (PMC 1009)

50) Mernadas de myo Çid Robado an el canpo (PMC 1736)

51) Quando fusco Iacob ad Aran a la tierra de Mesopotamia por miedo de Esau, so ermano, por la bendiccion que'.1 auia furtada (LR 2,5)

52) Vendido les a Alcoçer por tres mill marchos de plata (PMC 845)

53) Sive vineas, sive terras, vel ubicumque potueritis comparare et ubi habes comparatum in tota mea terra et in toto meo termino (Ub 383, 1070)

54) E esta heredat conomnada equanto a conprado e conprara enla uilla conomnada, que lo tenga en toda sua uita (DLE 267, 1207)

55) Todas las heredades $\tau$ las vjnnas que auje conprado $\tau$ ganado el monesterio de Sancto Domjngo de Silos ffata aquel tienpo en Uillas luengas de los labradores de Ualde Fande (DLE 219, 1236)

56) Conpro don Pedro, el camarero, I vinna en pago de Badaran, [j de] Semen Pastor, sulquera de la que ouo comprada de Iohannes Sancho (Emil 20, 1221) 
57) Los otros que tenien compras e non tornauan pecha ninguna [...] por $\mathrm{C}$ soldadas, o end a iuso, que aia compradas contandolo quomo fo conprado (Emil 47, 1237)

Por el contrario, aquellos verbos de adquisición y ganancia que no son términos causativos dentro de sus paradigmas léxicos presentan un grado de transitividad menor, hecho que incide en una mayor ambigüedad a la hora de interpretar estos ejemplos. A diferencia de los ejemplos anteriores con verbos de transferencia y pérdida de posesión, estos ejemplos admiten bastante bien la lectura resultativa: a medida que nos alejamos hacia la derecha en (31), disminuye el grado de transitividad y, con él, decrecen también la causatividad y la agentividad. Esto es lo que sucede con accipio (58), recibir (59), pagar (6061), o ganar (62-63), verbos que presentan un grado de ambigüedad mayor y vacilan entre la lectura resultativa y la de TA. La semántica de estos verbos es de carácter más durativo, y admiten mucho mejor que dar o donar la lectura resultativa 'os tengo pagado', 'no tenía pagadas las rentas', 'tiene ganado el castillo', ya que en estos casos el sujeto es poco agentivo, y menor el grado de causatividad del verbo.

58) Iuxta malleolo de Milian que habuit creatum domno Nunno de Zubazu, in precio quantum ad nos et tibi placuit, id est in viginti solidos, et totum precium habemus acceptum (...) Et totum precium habeo ad me acceptum (...) Totum precium habeo acceptum a me (Led 285, 1101)

59) Que fecha su cuenta entre amos a dos de lo que Don Lop auje recebido de quatro mil morabedis que el auje prestados al deuand dicho obispo por quitar en Francia los debdos que el obispo auje fechos en Roma (DLE 88, 1229)

60 ) et per las rendas ke toviera de vos et non vos las avie pagadas (Oñ 509,1247 )

61) Pagado uos he por todo a que(te año (PMC 1075)

62) Ganada a Xerica $\tau$ a Onda por nombre (PMC 1327)

63) Sacolos a selada, el caftiello ganado a (PMC 631)

\subsubsection{Verbos de comunicación y actos performativos}

El verbo prototípico de los verbos de comunicación es, sin duda, el verbo decir. Este verbo está íntimamente relacionado con dar, puesto que la afinidad significativa entre las acciones causativas de donación (transmisión de una posesión) y comunicación verbal (transmisión de información) es muy estrecha, por lo que parece plausible pensar en un mecanismo de extensión metafórica: dar es a decir como recibir a oir ${ }^{56}$. Estos verbos presentan dos modalidades de uso bien diferenciadas: la primera consiste en el uso estrictamente proposicional de estos verbos que, generalmente, denotan acciones puntuales y muestran

${ }^{56}$ Domínguez, op. cit., pág. 80. Que los términos complementarios do.-accipio son análogos de dico.-audio, lo corrobora el comentario de Servio a Virgilio: accipe 'audi', ut contra da 'dic' (Serv. ad Verg. Aen. 2, 65), Martín Rodríguez, op. cit., pág. 139. 
una estructura triactancial $(64,66-67)$, hecho que aumenta el grado de transitividad y favorece la lectura temporal. Por ejemplo, (64) parecen ser un TA, ya que muestra un uso ditransitivo de decir, que además aparece con su objeto directo canónico, una subordinada completiva.

64) Sciatis quod mihi habent dicto quod illos christianos quando se vadunt lures aixaricos (Lac 184, 1129)

65) La orden sea tenuda de recebir los morauedis $\tau$ la mengua deste ganado de atal fijo qual yoe dicho (DLE 279, 1239)

66) Mas a la fina da enponzonoronlo sos uassallos, e murie assi como l'auia dito Aristotus (LR 9, 29)

67) Efto les ha dicho, $\tau$ el moro fe torno (PMC 2686)

La segunda modalidad de uso consiste en el uso de referencia metadiscursiva (68-71), que tiene como objeto subrayar la relevancia en el aquí y ahora de la comunicación de lo dicho anteriormente ${ }^{57}$. Este uso metadiscursivo no muestra tan a las claras como el uso proposicional la temporalización de la perífrasis: (68-69) son ejemplos ambiguos (nótese que no llevan dativo; la presencia del dativo favorece la interpretación temporal) y vacilan entre una lectura temporal y una resultativa 'tener dicho, llevar dicho', más claro en (68), a causa de la concordancia, que en el ejemplo (69). No obstante, creo que en (70-71) es la interpretación temporal la que prevalece.

68) Otorgaronli que debe pacer e jacer e taiar e labrar el monesterio $\tau$ estas III casas que auemos dichas de suso (DLE 92, 1238)

69) Desta heredat, que de suso auemos dito, es la una pieça en Anamaça ola Penna Amariella (DLE 113, 1212)

70) Fablo Martin Antolinez, odredes lo que a dicho (PMC 70)

71) Tro aqui auemos comtado de los reies de Castiella (LR 15, 28)

Dentro de los verbos de comunicación podemos agrupar también a los verbos que designan actos performativos, como vedar $(93,103)$, obligar (91), mandar (72) o jurar (73), ejemplos en los que se hace muy difícil decidir si prevalece la lectura temporal o la resultativa. Por último, los actos comunicativos se revelan como un contexto particularmente proclive a la reinterpretación de haber + pp como TA, ya que favorecen especialmente la lectura de 'relevancia presente', puesto que el hablante asume la responsabilidad de lo que ha dicho ${ }^{58}$.

${ }^{57}$ Rolf Eberenz, «Como avemos dicho/diximos de suso...: los perfectos simple y compuesto en la referencia metadiscursiva del espariol medio», en Actas del V Congreso Internacional de Historia de la Lengua Española, M." Teresa Echenique, Juan Sánchez Méndez y Francisco Javier Satorre Grau (eds.), Valencia, Gredos, 2002, págs. 567-581.

${ }^{58}$ Kathleen Carey, «The Grammaticalization of the Perfect in Old English», en W. Pagliuca (ed.), Perspectives on Grammaticalization, op. cit, págs. 103-117; Jacob, «A propos de la périphrase habeo + participe», art. cit., pág. 375 . 
72) Que non falieffen delo que el Rey auye mandado (PMC 2984)

73) Ca affil dieran la fe $\tau$ gelo auien iurado (PMC 163)

\subsubsection{Verbos de acción}

El verbo prototípico de este dominio semántico es el verbo hacer. Hacer es también el verbo causativo por excelencia, y la causatividad el grado más alto dentro de la transitividad. Los usos causativos con el verbo hacer muestran, sin lugar a dudas, un uso totalmente temporalizado de la perífrasis (74-76). Como hemos visto anteriormente $(\$ 2, \mathrm{~V})$ solo los TA (pero no los resultativos) admiten predicados secundarios, de modo que (76) permite únicamente la lectura temporal.

74) Et auia feito fer cielo d'aramne e sol e luna \& estellas (LR 12,12)

75) A caualleros $\tau$ a peones fechos los ha Ricos (PMC 848)

76) E por la auleza que fizo, matoron lo' sos omnes, que muitos d'ellos auia feitos cornudos (LR 14,4)

Hay que destacar el hecho de que en la mayoría de los ejemplos que documento en el Corpus A con el verbo hacer, este se halla sometido a un proceso de abstracción, pues denota la realización de actos jurídicos abstractos (77-82), más que la realización de hechos físicos concretos, por lo que la relevancia pragmática se ve desplazada del 'resultado presente' a la 'relevancia presente'. Este proceso de abstracción aleja a haber hecho de su significado físico originario (tener hecha una casa, tener hecha la cena, acciones télicas con resultados físicos visibles) y lo acerca a la lectura como TA.

77) Placuit mihi et dono tibi Lop Iohannes de Tarazona propter servicium quod mihi habes factum et facis cotidie in presenti ( $\operatorname{Lac} 55,1118$ )

78) Por muchos e grandes seruitios que nos a fecho el nuestro amado filio don Mi- . gael Esteuanez (DLE 274, 1221)

79) et iam habeo tibi missas meas alias cartas, et ego dixi tibi et non habes hoc factum (Lac 96, 1124)

80) Sabida cosa sea (...) Ke me echo fiador e depdor a uos abbad don Iuuannes a a uuestro conujento por las rendas de Sancta Maria de Cannas de .XXVI. annos ke non pago (DLE 89, 1229)

81) dona Alvira uxor Petri de Cascant atorgavit istud suprascriptum impignoramentum et fidanças quod habebat factum maritus suus in Tutela (Lac 411, 1174)

82) sean tenudos el abbad $\tau$ el conuiento de dar (...) .Dtos. moravedis $\tau$ y el paramiento $\tau$ el plecto que an fecho (DLE 184, 1231)

83) Deftas mis ganançias que auemos fechas aca (PMC 1273)

En ambos corpus (A y B) haber hecho se utiliza especialmente para designar acciones pasadas con relevancia presente, con el objetivo de resaltar o subrayar los méritos de uno de los participantes. En mi opinión, es posible explicar este uso a partir de un mecanismo de transferencia metafórica: se con- 
ceptualiza en términos de posesión los hechos o méritos propios $(77-78,83)$ y las acciones con relevancia jurídica (79-82); esta posesión metafórica incide en la responsabilidad y en el grado de involucración del sujeto en el evento denotado por haber + pp. Particularmente interesantes resultan (77.78), porque designan un acto de reciprocidad por los servicios prestados (acción moral): como ha indicado Lakoff, el esquema metafórico más usual para los actos de retribución o reciprocidad moral es justamente el esquema de transferencia material $^{\text {s9. }}$.

Otros ejemplos con verbos de realización los podemos encontrar con los participios completum (84), vencido (85-86) y complidos (87), ejemplos todos ellos que apuntan más a la lectura temporal que a la resultativa (85 lleva dativo, rasgo que potencia la transitividad).

84) Et hoc totum quam in hanc cartulam resonat, quantum inter nobis bene complacuit conpletum havemus et apud te Enneconem abbatem et apud fratribus tuis non remansit debitum (On 41 1056)

85) E siento fazeden otorgo que uençudam aueder (RA 123)

86) E falle por pesquisa derechera que aquel molino et aquellas heredades sobredichas, que devien seer del monesterio de Onna derechamientre e di por caydos a fijos de Garci Ferrera e a sos herederos, e que avien vençudo el abbad e el convento de Onna (Oñ 459,1230 )

87) E si por auentura el mi fijo muriere ante que los .xiij. annos aya complidos (DLE 279, 1239)

\subsubsection{Verbos de movimiento y dirección}

Los participios de verbos transitivos de movimiento y dirección que documento con mayor frecuencia guardan una estrecha relación con los verbos de posesión, adquisición y pérdida. La equivalencia entre las acciones de darlenviar, sacarlquitar en alguno de mis ejemplos muestra un más que probable mecanismo de transferencia conceptual. Por ejemplo, en (88) mittere cartas lleva implícita la pérdida de una posesión, con la idea expresa de movimiento, y en (91) el verbo sacar se relaciona con la carencia de una posesión, puesto que en este caso, el significado del verbo equivale a 'quitar'. Al igual que sucedía con otros grupos verbales, la presencia de un tercer argumento aumenta el gra-

59 Robin Lakoff, «The Metafor System for Morality», en A. E. Goldberg (ed.), Conceptual Structure, Discourse and Language, Standford, CSLI, 1996, págs. 249-266 (pág. 253). Lakoff señala que "where you doing something good for me places me in your "debt", and I can repay what I "owe" by doing something equally good for you», observación que se ajusta plenamente a los ejemplos (77-82), donde la estuctura haber + pp entra en correlación con algunos verba dandi (dono, pago, atorgavit). En particular, (77-78) son los ejemplos que más claramente revelan el valor de TA, quizá por ser ambos ditransitivos y porque en el segundo incluso no hay concordancia. 
do de transitividad, refuerza la lectura temporal y dificulta la interpretación resultativa (* tal don me tiene enbiado).

88) et iam habeo tibi missas meas alias cartas, et ego dixi tibi et non habes hoc factum (Lac 96, 1124)

89) Gradefcolo a myo Cid que tal don me ha en biado (PMC 1856)

90) De toda la fu quinta el diezmo la mandado (PMC 1798)

91) dizien que demandando prouecho por ala ecclesia de Siguenza avien sacado sub contractu una summa de pecunia en la cort de Roma $\tau$ auten obligada la camera del cardenal don Gil (DLE 255, 1239)

92) Por defender $\tau$ guardar la ecclesia de todo danno $\tau$ de toda despesa o de pena que podrie venir o contecer por occasion de debdo que ouiesse saccado Garci Gilez $\tau$ Pero Sanchez (DLE 255, 1239)

\subsection{Modalidad (G)}

El paradigma que presentan los TA en nuestros dos corpus es altamente defectivo: no hay ejemplos de formas condicionales ni futuras en el indicativo, y tan sólo aparece un caso de futuro de subjuntivo (43). La escasa frecuencia de estas formas obedece al marcado contenido modal que poseen futuros, condicionales y las formas del subjuntivo, ya que todos ellos se relacionan más con la modalidad epistémica y con la expresión de contenidos no factuales e irreales que con la categoría verbal 'tiempo'. Las formas de pasado del indicativo, por el contrario, denotan prototípicamente eventos pasados, factuales y reales ${ }^{\omega}$. La menor frecuencia del subjuntivo hay que relacionarla con su carácter marcado respecto al indicativo y con el hecho de que la irrealidad, denotada a veces por el subjuntivo, disminuya el grado de transitividad de la cláusula.

Las formas que presentan modalidad irreal generalmente favorecen la lectura resultativa, como muestra el contraste entre los pares de (93) y (94): vetar en subjuntivo (93a) no permite más lectura que la resultativa, mientras que cuando el modo seleccionado por el verbo es el indicativo, el ejemplo admite las dos lecturas (93b). Lo mismo sucede en (94a): el obispo don Jerónimo le pide al Cid que le otorgue las primeras heridas del combate; es el Cid, y no el

${ }^{60}$ Givón, op. cit., págs. 302-305. En el corpus A, solo 9 ejemplos presentan modo subjuntivo $(15,25 \%)$, mientras que 50 ejemplos están en indicativo $(84,75 \%)$; en el corpus B los porcentajes para el indicativo son de un $97,47 \%(193 / 198)$, únicamente un escaso $1,51 \%(3 / 198)$ manifiesta modo subjuntivo y un $1.01 \%$ (2/198) modo imperativo. También existe un caso aislado de infinitivo compuesto. La primacfa del indicativo puede atribuirse a su carácter menos marcado, pero aún apelando a la marcación, las frecuencias de aparición de formas subjuntivas son demasiado escasas. Es posible que las diferencias de uso del subjuntivo entre los dos corpus (más usado en el corpus A que en el B) se deban a motivos de tradición textual: por lo general, los textos jurídicos (documentos notariales y fueros) usan más el subjuntivo que otro tipo de textos. Aún asi, insisto, las frecuencias de uso del subjuntivo son muy bajas, y creo que la razón hay que buscarla en los factores relacionados con el grado de transitividad. 
obispo, el agente del participio otorgar, y también el sujeto sintáctico de la secuencia: no hay ninguna posibilidad de lectura temporal en este ejemplo. Por el contrario, (94b), en modo indicativo, se acomoda mejor a la lectura temporal. Caso análogo es (95), único ejemplo de habria + pp en todo el corpus que, en cualquier caso, es una construcción resultativa y no un TA: la irrealidad denotada por habría dificulta la lectura temporal.

93) a. licet allii rustici illius supradicte ville vetatum habeant aliquem terminum ad pastum peccorum (Ub 146, 1013) 'aunque aquellos aldeanos tengan prohibido apacentar ganado en aquel lugar'

b. El rey lo ha uedado, anoch del etro fu carta (PMC 42)

94) a. Las feridas primeras que las aya yo otorgadas (PMC 1709)

b. si se acaycir que yo hi fizies alguna malfetria contra esto que he oforgado (Trian 150, 1247)

95) Nin entrarie enela tigera, ni vn pelo non aurie taiado (PMC 1241)

\subsection{Factores relativos al objeto $(A, I, J)$}

Una vez constatada la pertinencia de los parámetros Quinesis (B), Puntualidad (D) y Modalidad (G) en relación con los lexemas verbales más proclives a ser interpretados como TA en las construcciones de haber $+\mathrm{pp}$, quedan por examinar los otros parámetros condicionantes de la transitividad y relativos al objeto (A, I, J). En el corpus A, únicamente tres casos (3/59) carecen de objeto sintáctico expreso; cinco casos en el corpus B (5/198). La ausencia de objeto en estos ejemplos es exclusivamente sintáctica, ya que para la correcta interpretacion de la secuencia hay que sobreentendender la existencia de un objeto subyacente (96). La aparición de casos haber + pp con predicados semánticamente impersonales (97) y con verbos intransitivos inacusativos (98) e inergativos (99) constituye una novedad del corpus B respecto a los datos del corpus A.

96) Los dos han arrancado [a su adversario]: djreuos de Muno Guftioz (PMC 3671); Sicut filio meo carissimo habui datam [donationem] et tenuit sine ulla temptatione (Ub 108, 992)

97) Falido $a$ amyo Çid el pan $\tau$ la çeuada (PMC 581); AMinaya Lx.v. caualleros $a$ creçidol han (PMC 1419)

98) Tornan fe con las duexias, a Valençia an entrado (PMC 2247); Toda efta ganançia en fu mano a raftado (PMC 1733)

99) Los yfantes de Carrion bien an caualgado (PMC 2246); Quando ouo corrido, todos fe marauillauan (PMC 1590)

Estos ejemplos no admiten otra lectura que la temporal y garantizan la existencia de TA en español antiguo. Esta es una importante diferencia entre el latín y el romance, ya que en latín no se han podido documentar ejemplos de este tipo, puesto que todos los casos encontrados llevaban siempre $\mathrm{OD}^{61}$. Sin 
embargo, las frecuencias de aparición en el corpus de este tipo de predicados son infimas: ningún caso en el Corpus $\mathrm{A}$, cinco ejemplos de haber + pp con verbos intransitivos, cinco con verbos inacusativos y tres ejemplos con verbos semánticamente impersonales en el Corpus $\mathrm{B}^{62}$. El resto de los ejemplos del corpus, quitados estos trece casos, presentan siempre dos o más participantes (A)

La mayoría de los verbos documentados muestran una preferencia abrumadora por el objeto directo individualizado (J): en el Corpus A, un 88,13\% (52/ 59) de los objetos son determinados (sustantivos determinados, pronombres, objetos clitizados o cuantificadores universales), frente a un $5,08 \%$ de no determinados ( 3 casos); porcentajes a los que hay que unir los tres casos únicos de objeto implícito y otro caso más donde el objeto es una oración subordinada sustantiva. Un objeto determinado no solo conlleva un grado de transitividad mayor, sino que también potencia la deixis de la cláusula, y el tiempo, a diferencia del aspecto, es también una categonáa deíctica.

La Afección del objeto (I) es un factor crucial, porque la interpretación resultativa se ve favorecida si el grado de afección del objeto es máximo. La razón estriba en que la perfectividad es mury afín a la noción pasiva: si se alcanza de lleno la perspectiva del objeto y la acción verbal provoca un cambio o resultado en las condiciones del objeto, a menudo este cambio desencadena un desplazamiento semántico del verbo hacia la Aktionsart de estado ${ }^{63}$. Por ello, los ejemplos que muestran una lectura más cercana a los TA seleccionan objetos de carácter abstracto, mientras que cuanto más concreto sea el objeto, más se acerca la construcción a la lectura resultativa. Esta interpretación es la que prevalece en los ejemplos (100 a-d), donde haber + pp se aplica a objetos concretos y máximamente afectados.

100) a. La lança a quebrada, al efpada metio mano (PMC 746) 'tiene la lanza quebrada'

b. Avié con el desarro las piemas embargadas (Mil 438a) 'tenía las piernas embargadas'

c. Et insuper regi terre persoluuant XII libras auri obrizi et nobis damnum restituat duplatum quod fecit et non habeant valorem factum eius (Oñ 45, 1063) 'que no tenga vallado hecho'

d. Nam et in medio ibi [basilica] quasi altarium de lapidibus factum habet (Peregrinatio 4,4 ) 'esta basilica tiene en su centro una especie de altar hecho de piedra'

\footnotetext{
${ }^{61}$ García Martín, op. cit., pág. 41.

62 Para la interpretacion de haber + verbos inergativos e inacusativos, vid. Javier Rodríguez Molina, «Ser + participio en español antiguo: perf́rasis resultativa, no tiempo compuesto», en Actas del $V$ Congreso Internacional de Historia de la Lengua Española, en prensa.

${ }^{63}$ De los diez factores que comprende la escala de transitividad (24), este es el único que contraviene la hipótesis transitiva, por las razones que acabo de exponer: la afectación del objeto conlleva una potenciación de la resultatividad y dificulta la lectura de TA.
} 
Me parece muy significativo el hecho de que los verbos que muestran un mayor grado de transitividad presenten objetos abstractos que no implican resultado físico. Por ejemplo, el verbo hacer selecciona objetos abstractos que expresan hechos de relevancia jurídica (servicio, fianza, paramiento), lo cual ayuda a potenciar la lectura temporal. Lo mismo sucede con dar y donar: con estos verbos aparecen como objetos conceptos abstractos (vuestro avere, almunias) o cuantificadores (todo cuanto, quod, etc...). Idéntica diferencia observamos también en el caso de decir: en (68-69) el valor de TA no está tan claro como en (64), y precisamente (68-69) llevan objetos directos concretos (esta heredad, estas casas), mientras que en (64) el objeto es una subordinada completiva. Caso parecido lo constituyen los ejemplos (91-92) con sacar: sacar debdo, sacar una suma de dinero, ejemplos en los que observamos un desplazamiento metafórico desde el dominio físico primigenio del verbo sacar a un dominio semántico más abstracto. La preferencia por el evento abstracto nos la confirman también el Cid y los. Milagros de Berceo, ya que las únicas veces que aparecen los participios sacado (101) y metido (102) en dichos textos, éstos hacen referencia a hechos abstractos, y no a movimiento físico concreto:

101) Sacada me auedes de muchas verguenças malas (PMC 1596); asme oy sacado de muy grand pobredat (Mil 655c); avielo la envidia de su siesto sacado (Mil $719 \mathrm{c})$

102) ASaragoça metuda la en paria (PMC 914); Aft lo an a(mado $\tau$ metudo en carta (PMC 844)

Además, los verbos que aspectualmente denotan acciones télicas, como hacer, presentan un carácter más durativo cuando el objeto es concreto (hacer una casa, escribir un libro), puesto que el estado resultante que a menudo provoca un cambio en las condiciones físicas del objeto, o bien incide en la afectación del mismo. De ahí que las construcciones con haber + pp referidas a las partes del cuerpo $(95,100 \mathrm{~b})$ reciban preferiblemente una lectura resultativa. Sin embargo, el carácter abstracto del objeto favorece un desplazamiento de la interpretación semántica desde la Aktionsart de estado resultante a la Aktionsart de acción. El evento, cuando el objeto es abstracto, tiene un carácter menos durativo y más puntual $\mathrm{y}$, por tanto, presenta un grado de transitividad mayor. Por último, estas construcciones con objeto abstracto (dar aver, fazer fianza, fazer servicio, pagar rentas, etc...) favorecen la lectura de 'relevancia presente', puesto que lo relevante son las consecuencias derivadas de estos hechos, al no expresar resultado físico, mientras que cuando el objeto es concreto, es la lectura de 'resultado presente' la que se ve favorecida. Cognitivamente es mucho más sencillo percibir resultados físicos (concretos) que resultados no físicos (abstractos), por lo que parece plausible que el valor resultativo se vea atemperado si el objeto directo o la semántica del evento son de carácter abstracto. 


\subsection{Polaridad $(F)$}

Únicamente cinco casos del Corpus A (un 8,47\%) manifiestan Polaridad negativa (F), frente a un $91,53 \%$ de los ejemplos que presentan Polaridad afirmativa, rasgo que incrementa el grado de transitividad. De estos cinco casos, tres solo admiten el significado resultativo $(16,100 \mathrm{c}, 103 \mathrm{a})$, uno es ambiguo (60) y otro (79) parece ser un TA, porque, pese a mostrar polaridad negativa, en relación con el resto de los parámetros presenta un elevado grado de transitividad. La polaridad negativa dificulta la lectura temporal, y favorece la resultativa, como muestra el contraste de (103), ya que (103a) únicamente admite la interpretación resultativa, mientras que (103b) admite las dos lecturas, resultativa 'le tienen vedada la compra' y temporal 'le han vedado la compra'.

103) a. Et illi de Villa Gundissaluo istas defesas non habuerunt deuetatas de pascere, solumodo de matera $\tau$ ligna cedere (DLE 71,1044 ) 'los de Villa Gundisalvo no tenían prohibidas estas dehesas para apacentar ganado'

b. Vedada lan conpra dentro en Burgos la cafa (PMC 62)

\section{5. 'RELEVANCIA PRESENTE' Y TEMPORALIDAD}

¿En qué consiste exactamente el valor de 'relevancia presente' que caracteriza a las Resultativas tipo II y a los TA? Daniel Jacob, ofrece, en mi opinión, la hipótesis más coherente y atractiva al respecto ${ }^{64}$. Según Jacob, el paso del valor resultativo al valor temporal se vio favorecido por la capacidad que tenía el verbo haber de atribuir a su sujeto ciertos valores pragmáticos, particularmente un valor deóntico: haber + pp expresaba la situación en la que se encontraba el sujeto ante las consecuencias de una acción de relevancia interpersonal. Este nuevo uso de la perífrasis servía para marcar la especial relevancia y prominencia discursiva que determinados hechos tenían para el participante codificado como sujeto y, en última instancia, para los participantes del acto comunicativo. Jacob identifica estos hechos relevantes como actos performativos, actos de los que se deriva una responsabilidad, un derecho, un mérito o una deuda. La perífrasis designa acciones cuyas consecuencias definen el vínculo del agente dentro de una red de relaciones personales.

Esto explica, según Jacob, el hecho de que los sujetos de habere sean personales en un $96 \%$ de los casos que recoge en su estudio, estadística corroborada por los ejemplos de mi corpus ( $\$ 4.1$ ). Además, muchos de los ejemplos que se inclinan por la lectura temporal $(33-34,51-52,66-67,77-78,84-85$,

(4) Sus trabajos «A propos de la périphrase habeo + participe», art cit, y « $i$ Representatividad lingtística... ", art. cit., son fundamentales para entender la evolución de los TA en español antiguo, ya que muestran la importancia de los factores pragmáticos en dicha evolución. 
88-89) muestran una estructura triactancial, en la que el dativo siempre hace referencia a otra persona involucrada en el acto expresado por el verbo. En conclusión, la perífrasis designa así actos visibles que implican al emisor y al receptor simultáneamente y que, por lo tanto, son susceptibles de ser considerados de especial relevancia para los interlocutores. En nuestros documentos, haber + pp aparece fundamentalmente en los mismos contextos que señala Jacob bajo la etiqueta de 'valor deóntico': actos comunicativos (64-73) y actos jurídicos, o de los que se derivan consecuencias jurídicas: donaciones (32-37, 40-42), compra-ventas (52-57), beneficios y exenciones materiales (77-78), prohibiciones (103 a-b) o sentencias (86). En este tipo de contextos, el uso de haber + pp no solo conlleva un grado de abstracción mayor que el uso puramente resultativo de esta construcción, referido a entidades físicas (100 a-d), sino que incide especialmente en la noción de 'relevancia presente'.

¿Qué relación hay entre la 'relevancia presente' y el desarrollo de la 'anterioridad' verbal? La temporalidad es una categoría gramatical deíctica mediante la cual se expresa la relación entre dos momentos temporales: el momento o punto de la línea temporal donde se sitúa el evento y un punto de referencia o de origen desde el que se orientan las tres relaciones temporales existentes: anterioridad, simultaneidad y posterioridad ${ }^{65}$. Esta relación puede producirse de forma directa 'me dijo la verdad' o bien de forma indirecta 'me había dicho la verdad', a través de un punto de referencia secundario relacionado también con el origen: es lo que sucede en los TA. La localización del punto de origen es variable, aunque generalmente suele coincidir con el momento de la comunicación, porque éste es el centro deíctico o punto cero que reúne las condiciones prototípicas del fenómeno de la deixis: a) personal ('tú' y 'yo'); b) espacial ('aquí) y c) temporal ('ahora'). La deixis es un tipo particular de referencia que se aplica únicamente a expresiones referenciales orientadas egocéntricamente ${ }^{66}$.

Dado que la temporalidad es una categoría deíctica, parece plausible suponer que la interpretación temporal de haber + pp se vea favorecida en aquellos contextos donde la deixis de la cláusula es elevada (puesto que la expresión de la temporalidad no es una propiedad exclusiva del verbo, sino que está determinada por la cláusula entera). En un sentido amplio, podemos interpretar que la 'relevancia pragmática' es deixis. En cualquier proceso en el que funcione la relevancia discursiva serán de importancia el hablante y el oyente y, por tanto, habrá sujetos personales. Al situar la relevancia pragmática del evento denotado por haber + pp en el 'aqui' y 'ahora' de la comunicación, se establece un vínculo deíctico entre estos dos momentos temporales: el evento previo y el

${ }^{65}$ Bernard Comrie, Tense, Cambridge, Cambridge University Press, 1985.

66 Comrie, op. cit., pág. 14-18. La deixis temporal, en particular, sitúa lo descrito en el discurso en relación con el momento en que tiene lugar el evento comunicativo. 
denotado por la construcción resultativa ${ }^{67}$. Este vínculo otorga cierta prominencia comunicativa al evento previo y propicia la reinterpretación temporal de la perífrasis, siempre y cuando, claro está, el grado de transitividad de la cláusula favorezca esta reinterpretación. Por otra parte, y centrándonos ahora en la estructura argumental, la necesaria correferencia de sujetos que se da en estas estructuras focaliza la relevancia pragmática en la esfera del sujeto. Y, como hemos visto, nuestros ejemplos muestran eventos que relacionan pragmáticamente al hablante y al oyente, y presentan sujetos de carácter personal (sumamente referenciales) en el $96,61 \%$ de los casos (\$ 4.1). En cuanto al tipo de $O D$, también hemos visto que el tipo predominante es el OD individualizado $y$, por tanto, altamente referencial. Los sujetos personales y los OD individualizados revisten un neto carácter deíctico y, de hecho, el carácter personal del sujeto favorece, en mi opinión, la orientación egocéntrica a la que he aludido anteriormente.

\section{CONCLUSIONES}

El origen del proceso de gramaticalización de haber + pp radica fundamentalmente en las construcciones resultativas de tipo II habere $+\mathrm{pp}(\$ 2.2)$. Estas construcciones poseían un valor pragmático específico, ya que servían para presentar al actante codificado como sujeto como el autor, el responsable o el beneficiario del estado resultante expresado por la perífrasis, con lo cual se sumaba a esta construcción un valor añadido de relevancia presente, valor que se hizo extensivo al oyente $y$, en general, a los participantes involucrados en el acto comunicativo. La suma de todos estos factores se corresponde con el valor deóntico del que habla Jacob ${ }^{68}$. Inicialmente, la construcción haber + pp se hallaba restringida a una reducida nómina de predicados, porque únicamente los verbos que aspectualmente denotan eventos télicos podían formar construcciones resultativas (tipo I y tipo II) transitivas con habere (13-14).

Las construcciones resultativas de tipo II constituyen el contexto idóneo

${ }^{67}$ Considero muy significativo el hecho de que la mayora de los tan citados ejemplos de Gregorio de Tours (autor del siglo VI d. C) aparezcan en discurso directo, hecho que, sorprendentemente, ha pasado prácticamente inadvertido a los investigadores. Entre ellos, el famoso ejemplo del obispo: 'Causatur monachus dicens: Ecce episcopum cum duce et civibus invitatum habes' (Vit. Patr. 3, 1) y algunos más de la Historia Franconum: 'Qui dixerunt: [...] promissum enim habemus de majoribus causis nihil sine ejes consilio agere' (Hist. Fr. 9,16) o 'Vade et dic ei : Scis enim quod foedus inter nos initum habemus, rogo ut te de meis removeas insidiis' (Hist. Fr, 5, 26). Cito por la edición de la Patrologia de J. Migne, S. Georgii Florentini Gregorii Turonensis Episcopi Opera Omnia necnon Fredegarii scholastici Epitome et Chronicum, Tumbout, Brepols, 1983.

68 Jacob, «A propos de la périphrase habeo + participe», art cit., $y$ « 2 Representatividad lingǘstica..,", art. cit. 
para que se produzca tanto el reanálisis (7) como el cambio semántico (8), debido a que presentan correferencia sintáctica explícita y obligatoria de sujetos y a que, en términos pragmáticos, favorecen la 'relevancia presente' de la acción previa que da lugar a la construcción resultativa. Aún así, el reanálisis no sucede de forma automática en cualquier ejemplo de Resultativa tipo II, sino que se requiere suficiente motivación extralinguística (pragmática) y lingüística (grado de transitividad) para que se produzca.

La adquisición del valor semántico de anterioridad es un fenómeno gradual que se encuentra orientado léxicamente y que guarda relación con el grado de transitividad del predicado (25 A-F), puesto que parece haber una relación directa entre grado de transitividad y reinterpretación semántica (§ 4). En español antiguo, la perífrasis se relaciona fundamentalmente con los dominios semánticos de posesión, comunicación, acción y movimiento.

Los verbos del dominio semántico de la posesión, al que pertenecía haber forman una red léxica entre sí, y es gracias a estas conexiones como se desencadena la interpretación de TA. Esta surge en los verbos que presentan un grado de transitividad mayor (dar, donar, dejar, etc...), porque un grado de transitividad elevado se traduce en una mayor dinamicidad y en una atenuación del valor resultativo. En esta reinterpretación de la perífrasis intervienen dos de los principales mecanismos de gramaticalización (15d): la metonimia y la metáfora. Metonimia porque el hablante focaliza la parte causativa de la relación semántica de la posesión (dar) y no la parte estativa (haber); metáfora porque podemos observar cómo los miembros causativos de la relación semántica de posesión muestran una clara preferencia por el objeto abstracto y, asimismo, presentan eventos con un grado de abstracción elevado (15e), lo cual redunda en la atenuación del valor resultativo. En los otros dominios semánticos también observamos cómo el grado de transitividad y los principales mecanismos de cambio semántico (metáfora, abstracción conceptual) intervienen decisivamente en la adquisición de valores temporales.

En definitiva, los verbos que se documentan con mayor frecuencia están relacionados semánticamente (pertenecen a dominios conceptuales afines) y presentan unas propiedades léxico-semánticas comunes: alta transitividad, estructura triactancial, causatividad, sujetos humanos y agentivos, etc. Por último, son verbos con una frecuencia de lengua muy elevada, debido a que denotan eventos particularmente susceptibles de ser catalogados como de máxima relevancia.

Fuera de estos grupos verbales, los ejemplos de haber + pp son prácticamente inexistentes, lo cual nos muestra que, en la etapa más antigua, esta construcción se hallaba constreñida por fuertes restricciones semánticas (15a). Poco a poco, la construcción va perdiendo restricciones contextuales y semánticas, y 
va ganando en extensión y generalización (15f). Lejos de considerar que el paradigma de los TA estaba firmemente asentado desde la época de orígenes, los datos parecen mostrar que esta estructura no se hallaba sino en su fase inicial de gramaticalización. La baja frecuencia de aparición (15b), la ausencia de un paradigma consolidado (puesto que no se documentan casos ni de habría + pp ni de habré $+\mathrm{pp}$ ) y las restricciones léxicas observadas invitan a una reconsideración del estado de la cuestión acerca del origen de los TA. La innovación existe desde época muy antigua, es cierto, pero el grado de difusión de la perífrasis en español primitivo era, a juzgar por los datos, bastante bajo: tanto si consideramos la estadística global de frecuencia sobre el número de ejemplos totales encontrados como si analizamos la frecuencia de uso de haber + pp en relación con los tipos de participios documentados, podemos observar la escasa implantación de estas construcciones en la lengua primitiva.

Los datos con los que contamos sobre la doble auxiliaridad del español antiguo proporcionan también un apoyo indirecto a las hipótesis expuestas en este trabajo: parece que la pérdida de ser está también relacionada con el grado de transitividad, con el papel temático del sujeto y con las propiedades aspectuales del predicado ${ }^{69}$. La sustitución ser $>$ haber como auxiliar de estructuras inacusativas se documenta antes en contextos donde el sujeto se acerca más al papel temático de proto-agente o donde se ha producido un proceso metafórico por abstracción que atenúa la percepción de resultados físicos concretos, tal y como sucede con nuestros ejemplos con haber en relación con el tipo de objeto.

Queda por ver en qué medida las hipótesis que aquí he manejado para el español antiguo son aplicables a los estadios más primitivos de las restantes lenguas romances. Si fijamos nuestro foco de atención en la semántica de estas construcciones, estaremos en condiciones de reconstruir con mayor precisión las etapas iniciales de gramaticalización de los TA en toda una familia lingüística, porque el análisis de las clases léxicas de participios que se combinaban con haber y de su frecuencia de uso nos proporcionará un índice relativamente seguro de comparación entre las diversas lenguas romances, nos permitirá establecer los cauces concretos de difusión de la perífrasis en cada lengua y, finalmente, ayudará a una mejor comprensión de la gramaticalización de los TA en otras lenguas.

${ }^{69}$ Thomas F. Shannon, «The unaccusative hipothesis and the history of the perfect auxiliary in germanic and romancen, en Historical Linguistics 1987. Papers from the 8th international conference on historical linguistics, H. Andersen y K. Koerner (eds.), Amsterdam/Philadelphia, John Benjamins, 1990, págs. 461-488; Raúl Aranovich, «The Semantics of Auxiliary Selection in Old Spanish», Studies in Language, 27: 1, 2003, págs. 1-37. 